\title{
Los derechos humanos de los hijos de los soldados alemanes tras la Segunda Guerra Mundial. El caso de Noruega*
}

\author{
The Human Rights of the German soldiers' children after \\ the Second World War. The Norwegian case
}

\author{
Soledad TORRECUADRADA GARCíA-LOZANO \\ Profesora titular de Derecho Internacional y Relaciones Internacionales \\ Universidad Autónoma de Madrid \\ s.torrecuadrada@uam.es
}

RECIBIDO EL 11 DE ENERO DE 2019/ ACEPTADO EL 29 DE ENERO DE 2019

Resumen: Los hijos de los soldados alemanes en zonas ocupadas durante la Segunda Guerra Mundial vivieron una situación difícil una vez concluida la contienda. Fueron niños que debieron crecer con el estigma propio de ser hijos del enemigo acompañado, en el mejor de los casos, cuando conviven con sus madres biológicas, con el que sufren ellas por haber elegido a un enemigo como pareja (si este fuera el caso). Un supuesto particular en este punto es el caso de Noruega, donde a estos menores se les unieron los niños del Proyecto Lebensborn, pues en este Estado se abrieron casi tantos centros como en Alemania. Todos ellos crecieron con el rechazo de las sociedades en las que habitaban que veían en ellos una prolongación de sus padres, que habían sido sus ocupantes, dispensándoles un tratamiento muy distinto del que por su edad merecían. Algunos de esos niños acudieron hace diez años al Tribunal Europeo de derechos humanos contra Noruega, al considerarse víctimas de la vulneración del Convenio Europeo por este Estado.

Palabras clave: Derechos del niño, Segunda Guerra Mundial, Tribunal Europeo de Derechos Humanos, Reparaciones, hijos del enemigo.

\begin{abstract}
The children of the German soldiers in occupied areas during the Second World War lived a difficult situation once the war was over. They were children who had to grow up with the stigma of being children of the enemy, which was accompanied that of their biological mothers who suffered for having chosen an enemy as a couple (if this was the case). A particular case in point is Norway, where the fate of these children was combined with that of the children born out of the Lebensborn Project since in Norway almost as many racial purification centers were opened as in Germany. All of them grew up with the rejection of the societies in which they lived that saw in them an extension of their parents, who had been their occupier, giving them a treatment very different from the one they deserved because of their age. Some of these children turned to the European Court of Human Rights ten years ago with a complaint against Norway, considering themselves to be victims of the breach of the European Convention by this state.
\end{abstract}

Keywords: Children Rights, Second World War, European Court of Human Rights, Reparations, Children of the Enemy.

Sumario: I. INTRODUCCIÓN. II. EL PROYECTO LEBENSBORN. III. LAS CONSECUENCIAS DE SER HIJOS DEL ENEMIGO EN NORUEGA. 1. Los hechos. 2. Los derechos. 3. El procedimiento de admisibilidad ante el TEDH. 3.1. Prescripción y reparación. 3.2. La doctrina del margen de apreciación nacional. 4. La potencial aplicación al caso de otras normas internacionales. IV. CONCLUSIONES.

* Realizado dentro del Proyecto La evolución de las instituciones jurídicas de protección de menores (financiado por el MINECO/FEDER, convocatoria 2015, referencia: DER2015-69261-R. Investigadora principal: Susana Quicios Molina. 


\section{INTRODUCCIÓN}

L a estigmatización que sufren los hijos del enemigo perdedor de una contienda es un objeto de análisis olvidado por el Derecho Internacional. El estudio de los crímenes sexuales en los conflictos armados me llevó a interesarme por los hijos nacidos de esos crímenes ${ }^{1}$, y ahora a la situación de los hijos de relaciones consentidas con soldados del Estado enemigo, perdedor de la contienda. Este propósito me ha conducido a conocer la realidad de los hijos de los soldados alemanes nacidos en territorios ocupados por el Tercer Reich, así como el Proyecto Lebensborn que, encontrando su origen en situaciones diferentes, tuvieron que sobrevivir a durísimas experiencias una vez concluido el conflicto por ser hijos del enemigo perdedor de la contienda, un enemigo que había sometido a los territorios ocupados a condiciones muy duras.

El caso de los niños de Lebensborn resulta especialmente cruel, dado que inicialmente se privó de afecto y entorno familiar a quienes fueron objeto de este proyecto y en la posguerra la situación, lejos de mejorar, empeoró considerablemente puesto que recibieron el rechazo social derivado de un hecho que no estaba en su mano cambiar: que su progenitor fuera un soldado enemigo. Este trabajo se centra especialmente en Noruega, al ser el Estado del que contamos con una mayor información debido al procedimiento sometido en 2003 al Tribunal Europeo de Derechos Humanos (TEDH, en adelante), aunque existieron centros del Proyecto en otros territorios ocupados por el Tercer Reich y niños que fueron fruto de relaciones consentidas con ocupantes de los que no se cuentan con datos tan precisos, ello a pesar de que desde hace pocos años se está produciendo literatura (no académica) en lugares como Francia, donde se calcula que pudieron nacer cerca de 200.000 hijos de padre alemán durante la Segunda Guerra Mundial, en Finlandia 4.000, en Bélgica 40.000, en Holanda $20.000^{2}$, en los archivos daneses constan $5.579^{3}$.

Concluida la contienda, liberados los territorios de la ocupación alemana, los vencedores impusieron unas condiciones de vida que afectaron considerablemente a quienes se consideraron colaboracionistas con los antes ocupantes,

1 Vid. «Los hijos del enemigo: las víctimas silenciosas de los crímenes sexuales», Anuario Español de Derecho Internacional, 2017, $\mathrm{n}^{\circ} 33$, pp. 127-168.

2 Vid. Noticia en el diario Le Figaro: http://www.lefigaro.fr/actualite-france/2009/11/30/0101620091130ARTFIG00413-200000-enfants-de-soldats-allemands-seraient-nes-en-france-.php

3 http://www.krigsboern.dk/index.php/da/component/content/article/9-uncategorised/83english-resume 
lo que alcanzó evidentemente a las mujeres que tuvieron relaciones con soldados alemanes (en tanto que colaboradoras horizontales) y a sus hijos. A estos últimos, como niños que eran, la dura situación en la que debieron sobrevivir lastró su presente y, como todas las experiencias de la infancia, afectó negativamente a sus posibilidades de futuro.

En todas las contiendas nacen hijos del enemigo ${ }^{4}$, que cuando se trata del enemigo vencido se les denomina de forma peyorativa con independencia del lugar del mundo, el momento y características de los conflictos en los que hayan nacido ${ }^{5}$, con una intención evidentemente estigmatizadora. Cuando el enemigo es el vencedor de la contienda si existen tentaciones de discriminar no se exteriorizará del mismo modo que en el caso anterior ${ }^{6}$, aunque no es una garantía de ausencia de discriminación, pues todo depende del caso concreto y del contexto en el que se desenvuelven los niños en cuestión.

En este trabajo me centraré en un caso muy particular: el de los hijos de los soldados alemanes tras la Segunda Guerra Mundial ${ }^{7}$, cuya existencia en la

4 La definición de «Children born of war», según Mochmann I.C.; LaRSEN, S.U, «'Children born of war': the life course of children fathered by German soldiers in Norway and Denmark during WWII - some empirical results», en Historical Social Research, 33, 2008, 1, pp. 347 y ss., alcanza a todos aquellos que sean hijos de un militar enemigo, fuerza de ocupación, de un niño soldado o incluso más recientemente se han incorporado a esta relación los hijos de miembros de operaciones de mantenimiento de la paz, vid. en pp. 350-351.

5 Así, encontramos los enfants de boche en Francia (tras la Segunda Guerra Mundial), devil's children, en Rwanda, son/daughter of Kony, children of hate, genocidal children, unwanted children, children of bad memories o children of shame en Kosovo, Children of the enemy en el este de Timor, Dust of life o American infected babies en Vietnam, soldadito en Guatemala, Paraquitos en Colombia, los regalos de los soldados, bijo de nadie o fulano en Perú, En Noruega tyskeungar, «niños de alemanes», a los nacidos durante el periodo de la ocupación de la unión de un soldado alemán y una mujer noruega. Existen múltiples listados que contienen la denominación despectiva con la que se conoce a estos niños, esta está tomada de THEIDON, K., «Hidden in Plain Sight. Children Born of Wartime Sexual Violence», en Current Anthropology, vol. 56, suplemento 12, diciembre 2015.

6 Pensemos en los posibles hijos de las violaciones producidas en Alemania por los soldados aliados, que se calcula que fueron aproximadamente 860.000 según el dato obtenido en: https://www. francetvinfo.fr/monde/europe/allemagne/allemagne-la-fin-de-certains-tabous-sur-la-secondeguerre-mondiale_3067725.html, este dato también puede verse en: https://www.elmundo.es/ cronica/2015/05/17/55571f80268e 3edc718b4572.html, de ellas y de las relaciones consentidas con soldados aliados pudieron nacer 200.000 niños en Alemania y 20.000 en Austria: https:// www.lavanguardia.com/internacional/20170308/42633281873/libro-hijos-alemanas-soldadosaliados-segunda-guerra-mundial.html

7 Sobre los hijos de los crímenes sexuales, vid. TorrecuadradA, S., «Los hijos del enemigo...», op. cit. supra. Resulta paradójico que con la producción académica existente acerca de los crímenes sexuales -violaciones, matrimonios y maternidades forzosas- en los conflictos armados (vid. Por todos Lirola Delgado, I.; Martín MarTínez, M. Crímenes internacionales de violencia sexual y conflictos armados, Madrid, Aranzadi, 2016), no se haya trabajado ni siquiera mínimamen- 
posguerra aparentemente resultará más segura que la de los niños sin hogar por cuanto pueden contar con un entorno familiar protector, siempre que este exista y no les rechace o les acose, en cuyo caso, la situación será aún más complicada para ellos. En todo caso, por muy protector que resulte este entorno familiar, los niños tendrán que sobrevivir a la discriminación de la que son víctimas tanto ellos como sus madres, consideradas depravadas por haberse relacionado con los enemigos, bástenos aquí recordar a las femmes tondues en Francia $^{8}$.

En el caso de la Segunda Guerra Mundial, a los hijos de soldados alemanes hay que añadir los que crecieron en sus primeros años en locales del Proyecto de Lebensborn, bien porque nacieran allí o porque fueran secuestrados e internados en ellos para su nazificación. Resulta, cuando menos sorprendente la inexistencia de análisis jurídicos sobre la vulneración de los derechos (atribuible a los Estados vencedores de la contienda) de la que han sido víctimas quienes tuvieron la desgracia de encontrarse en este contexto. Solo a finales del siglo XX salieron a la luz sus circunstancias como consecuencia de la infructuosa demanda formulada al TEDH contra Noruega?.

te la situación de los niños nacidos como consecuencia de ellos. Uno de los motivos del silencio académico acerca de esos niños deriva de la ubicación del foco de atención en las víctimas de aquellos crímenes: las mujeres, identificando en el mejor de los casos a los hijos como víctima indirecta, secundaria o derivada de la violación, metodología que produce el alejamiento de los pequeños del centro de interés (vid. en este sentido CARPENTER, R.Ch. «Forced Maternity, Children's Rights and the Genocide Convention: A Theoretical Analysis», Fournal of Genocide Research, 2000, 2(2), pp. 213 y ss.

8 En el siglo XXI se han publicado obras que contienen los relatos sobre la situación en la que transcurrió su infancia. Ver, por ejemplo, PICAPER J-P.; NORZ, L., Enfants maudits. Ils sont 200000 , On les appelait les «enfants de Boches», Ginebra, Syrtes, 2004; MAROGER, K., Les racines du silence, Paris, Anne Carrière editeur, 2008; VIRGILI, F., Naître ennemi: Les enfants de couples franco-allemands nés pendant la Seconde Guerre mondiale, Paris, Payot, 2014. Sobre las mujeres que tuvieron una pareja alemana durante la Guerra, del mismo autor, France «virile»: Des femmes tondues à la libération, Payot, Paris, 2004; Bourdrel, Ph., L'épuration sauvage, París, 2008; Desmarais, J., Femmes tondues France - Libération: Coupables, amoureuses, victims, Quebec, 2011; FrÉTIGNÉ, Ph., La tondue 1944-1947, Paris, Vendémiaire, 2013; Fournie, P., Présumées coupables, Paris, 2016, entre otros.

9 La demanda fue introducida por siete personas que vivieron en centros del Proyecto Lebensborn y 152 personas más, a 112 de ellas no se les permitió unirse a la acción emprendida por los anteriores en los tribunales noruegos, por lo que iniciaron otra por su parte. Los 44 restantes no iniciaron acción alguna por considerar que los insatisfactorios resultados obtenidos por los anteriores les resultaban a ellos igualmente aplicables. Decisión de inadmisión en el caso Werner Hermann Thiermann and others v. Norway, de la primera sección, de 8 de marzo de 2007, en la demanda 18712/30. 
El ordenamiento internacional actual ignora a los hijos del enemigo, salvo que sean fruto de maternidad forzosa, en cuyo caso hay referencias marginales entre las categorías especiales de niños en los conflictos armados en la Declaración y recomendaciones sobre los derechos de los niños en los conflictos armados, conocida como Declaración de Ámsterdam ${ }^{10}$. Este texto se limita a recomendar la realización de esfuerzos para evitar su estigmatización ${ }^{11}$, a pesar de lo cual su mera mención resulta un hallazgo y un reconocimiento de su existencia y en esa medida un avance, aunque exclusivamente respecto de las categorías indicadas. La ignorancia del ordenamiento internacional sobre estos niños que se encuentran en una situación de gran vulnerabilidad resulta llamativa, dado que, a diferencia de los niños afectados por los conflictos armados, la situación más dura de su existencia se mantiene y agudiza concluida la contienda (la posguerra suele ser más larga que la guerra), debido a la discriminación de la que son objeto en las comunidades de origen de sus madres. Se trata de niños a los que D. Seto considera como «a symbol of collective victimhood and a spectacle to discipline a nation damaged by conflict» ${ }^{12}$. Es cierto, por otra parte, que la Convención sobre los derechos del niño es aplicable a todos los niños sin excepción y les proporciona la protección necesaria para evitar la discriminación de la que han sido víctimas en otras épocas. Sin embargo, conocida la historia, resultaría conveniente evitar la reproducción en el futuro de situaciones como las que tuvieron que sufrir los hijos de los soldados alemanes nacidos en territorios ocupados, aunque la práctica es tozuda en indicarnos lo contrario.

En adelante estudiaremos la estigmatización de la que fueron objeto estos «hijos del enemigo» una vez concluida la contienda, desde la perspectiva de cumplimiento de los derechos del niño. Esta situación vulnera los derechos de los que son titulares todos los menores y de cuya garantía es responsable el Estado ${ }^{13}$. Para ello, vamos a utilizar como hilo conductor la situación

10 Se refiere a los niños «who is pregnant as the result of rape or other sexual abuse should have the same rights as an adult woman. El texto completo de la Declaración y las recomendaciones aludidas se encuentra en The International fournal of Children's Rights, 1994, 413 y ss.

11 El mismo texto indica: «Every effort shall be made to prevent the danger of stigmatisation of children born as the result of rape»

12 Setтo, D., «Children Born of Wartime Sexual Violence and the Limits of Existence», en Peacebuilding, vol. 3, 2015-2, la versión electrónica de este estudio puede descargarse en la siguiente dirección: http://tandfonline.com/doi/full/10.1080/21647259.2015.1052631?src=recsys\&

13 El artículo tercero de la Convención sobre los derechos del niño establece el compromiso de los Estados de «asegurar al niño la protección y el cuidado que sean necesarios para su bienestar, teniendo en cuenta los derechos y deberes de sus padres, tutores u otras personas responsables de él ante la ley y, con ese fin, tomarán todas las medidas legislativas y administrativas adecua- 
protagonizada por los niños noruego-alemanes, a los que se incorporan los del proyecto Lebensborn, al finalizar la Segunda Guerra Mundial. Cuestión sobre la que el TEDH omitió pronunciarse. Para ello, en un primer momento nos centraremos en profundizar en el proyecto en cuestión, deteniéndonos después en realizar un análisis crítico sobre el pronunciamiento del Tribunal, terminando, como es habitual en este tipo de trabajos, con unas conclusiones.

\section{EL PROYECTO LEBENSBORN}

El proyecto Lebensborn fue uno de los elementos que formaron parte del programa racial del nazismo, puesto en marcha en Munich el 12 de diciembre de 1935 por Heinrich Himmler como agencia de las $\mathrm{SS}^{14}$. El propósito eugenésico de lograr una raza superior que gobernara el mundo ${ }^{15}$ implicaba seleccionar a los progenitores para lograr niños arios (aquellos que no se acomodaran al modelo deseado, eran enviados a campos de trabajo o exterminados), que serían formados conforme a los criterios e ideas educativas del nazismo. Además de lo anterior, a través del proyecto se administraban las ayudas dirigidas a las familias numerosas que tuvieran hijos que reunieran las características acordes con los criterios raciales del régimen. Para lo primero, se crearon unas maternidades en las que se acomodaba y cuidaba de las madres, en las que tenían lugar los alumbramientos, que servían también como orfanatos en los que se educaba a los niños en el nazismo.

das». En todo caso, aunque en aquellos momentos los derechos del niño no estaban desarrollados como en la actualidad, lo cierto es que existían mimbres suficientes como para considerar que se estaban vulnerando de forma grave y sistemática sus derechos.

14 Ver en Thompson, L.V. «Lebensborn and the Eugenics Policy of the Reichführer-SS», en Central European History, 4, 1971, pp. 54 y ss.; Originariamente fueron centros creados para permitir el alumbramiento secreto de hijos de madres solteras (arias, evidentemente) como una forma de reducir el número de abortos entre la población alemana, incrementando la natalidad de niños arios pues, en su idea de futuro, para dominar el mundo precisaban multiplicar los nacimientos que se producían fruto de relaciones matrimoniales. También, en BERGER, K. «Children of the Lebensborn: the Search for Identity in Selected Literary Text of the Berlin republic», en Focus on German Studies, 15, 2008, pp. 104 y ss.

15 Sobre el racismo nórdico, vid. FIELD, G. G. «Nordic Racism», Fournal of the History of Ideas, vol. $38, \mathrm{n}^{\circ} 3$, sept. 1977 , pp. 523 y ss., en las pp. 529 y ss. Analiza el nazismo desde esta perspectiva. Sobre Lebensborn, puede verse THIOLAY, B., Lebensborn. La fabrique des enfants parfaits, Paris, Flammarion, 2012. 
La creación de Lebensborn es una consecuencia de los actos normativos enmarcados en la política eugenésica que perseguía la pureza racial y la supremacía aria, motivo por el cual solo se permitían matrimonios entre personas aptas para darle hijos al Reich. Con este propósito se había adoptado la Ley para la Protección de la sangre y el honor alemanes, de 15 de septiembre de $1935^{16}$ y un mes más tarde, la Ley de Protección de la Salud Hereditaria del Pueblo Alemán ${ }^{17}$, que establecía la exigencia de un certificado en el que se hiciera constar la ausencia de enfermedades hereditarias y/o contagiosas como requisito inexcusable para poder celebrar matrimonio. En realidad, esta última Ley contenía una interpretación extensiva de lo establecido en la orden de compromiso y matrimonio de las SS adoptada el 31 de diciembre de 1931, que precisaba la autorización de la Oficina de la raza y reasentamiento (RuSHA) ${ }^{18}$ para contraer matrimonio.

Por otra parte, al constatar que el número de nacimientos dentro del matrimonio resultaba insuficiente para lograr el objetivo propuesto, se alentaba a los hombres aptos para la procreación de niños arios a la paternidad extramatrimonial, siempre que la elegida resultara adecuada a los criterios establecidos por el régimen a estos efectos ${ }^{19}$. De este modo, toda relación que pudiera calificarse de conformidad con el ordenamiento nazi como «ultraje a la raza», concepto amplio y subjetivo, permanecía al margen de la legalidad, como puso de relieve el asunto Katzenberger ${ }^{20}$.

16 Una traducción del texto en: http://ficus.pntic.mec.es/jals0026/documentos/textos/leyesnuremberg.pdf+

17 Un interesante estudio en: CZECH, H., «Santé publique, hygiène raciale et eugénisme sous le Troisième Reich: l'exemple de Vienne», Revue d'Histoire de la Shoah, 2005/2 No 183, pp. 423 y ss.

18 Ver en este sentido, GuERra-García, Y.M.; Ávila-Morales, J.C.; ACuÑA-BARRANTES, H., «La búsqueda de la raza perfecta. Ideas sobre procreación, vejez y eugenesia», Revista Eleuthera, 13, pp. 64 y ss. En el proceso ${ }^{\circ} 8$ de Nuremberg se declaró culpable de crimen contra la humanidad a Fritz Schwalm, Jefe de Estado mayor de RuSHA, condenándole a diez años de prisión; Herbert Hubner, Representante de RuSHA en Polonia (quince años), Otto Hofman, Jefe de RuSHA hasta 1943 (25 años) y Webner Lorenz, Jefe de la oficina de enlace de alemanes étnicos situados fuera de Alemania (20 años). Vid. en https://www.loc.gov/rr/frd/Military_Law/pdf/ Law-Reports_Vol-13.pdf

19 Sobre las medidas adoptadas para incrementar la natalidad dentro y fuera del matrimonio puede verse VirgiLI, F., Naître ennemi. Les enfants de couples franco-allemandes nés pendant la Seconde Guerre Mondiale, París, Payot y Rivages, 2009, pp. 46 y ss.

20 Ver en Steinweis, A. E.; Rachlin, R. D. (eds.), The Law in Nazi Germany: Ideology, Opportunism, and the Perversion of Justice, Nueva York, Berghahn, 2013, también en Roland, P., The Nuremberg Trials: The Nazis and Their Crimes Against Humanity, Londres, Arcturus Publishing Limited, 2012, Capítulo 6. Asunto que aparece en la película de Stanley Kramer (1961) Fudgment at Nuremberg como caso Feldenstein. 
El sistema de multiplicación de nacimientos de raza aria discriminaba entre los hijos matrimoniales ${ }^{21} \mathrm{y}$ los que nacían en estas instalaciones. Los primeros se mantenían en su entorno familiar y conservaban su nombre y apellido, mientras los segundos eran separados de sus madres pocos meses después de su nacimiento -pues carecían de cualquier derecho sobre los pequeños-, recibían nombre y apellido tras el rito de iniciación establecido al efecto -una especie de bautismo nazi-, al considerarse hijos del régimen, desapareciendo cualquier referencia a su familia biológica, lo que después de la guerra dificultó su reencuentro.

Si bien el propósito del Proyecto Lebensborn inicialmente fue el que indicamos, con el paso del tiempo desafortunadamente se amplió. Así, se ha documentado el secuestro de niños en el este europeo ${ }^{22}$, por parecerles racialmente adecuados. Si los pequeños superaban con éxito los severos análisis antropométricos a los que eran sometidos ${ }^{23}$, se les acogía en estos centros para educarlos conforme a los criterios supremacistas preconizados por el nazismo en estos orfanatos-maternidades. Concluido el programa de germanización ${ }^{24}$ se les en-

21 A la bibliografía citada supra en notas 10, 11 y 15, puede añadirse LóPEZ DE CASENAVE, L., Los otros niños del pijama de rayas: los ángeles del Holocausto, Barcelona, Robinbook, 2009.

22 Id. Thompson, op. cit. (p. 96 y ss.) indica que en Oberkrain, Eslovaquia, quedaron huérfanos unos 600 niños, fruto de la operación Aktion Enzian, en la aldea Checa de Lídice o en Praga también se produjeron menores huérfanos, los que físicamente parecían arios fueron sometidos a los análisis antropométricos de rigor. Si el resultado era favorable, se les incorporaba en el programa, de lo contrario se les mandaba a campos de trabajo, exterminio o se les utilizaba en experimentos médicos.

23 Se calcula que entre 150.000 y 200.000 niños polacos fueron trasladados para incorporarlos a este proyecto, debido a su apariencia física. Ver en este sentido «Lebensborn: el programa nazi que secuestró a miles de niños eslavos», en Russia beyond the headlines, el texto puede leerse en https://es.rbth.com/cultura/2013/06/10/lebensborn_el_programa_nazi_que_secuestro_a_ miles_de_ninos_eslavos_28735 Ver también: http://www.elholocausto.net/parte04/0411.htm, http://www.cienciahistorica.com/2014/12/11/lebensborn-o-como-crear-una-raza-perfecta/ En el Tribunal de Nuremberg se afirma «The» Lebensborn «Society existed long before the war and was primarily concerned with running a maternity home. It was contended by the prosecution that, within the racial scheme for annihilating nations under German rule, it was responsible for kidnapping of foreign children for the purpose of Germanization.» Este texto se encuentra en la página 5 de las actas del tribunal en el caso ${ }^{\circ} 73$, Trial of Ulrich Greifelt and others. United States Military Tribunal, Nuremberg. 10th October, 1947-10 th march, 1948, en: http:// www.worldcourts.com/imt/eng/decisions/1948.03.10_United_States_v_Greifelt2.pdf

24 Puede verse http://www.bowin.eu/, foro de reunión de algunos de quienes fueron hijos del enemigo. Un proyecto de investigación europeo sobre esta cuestión en: https://www.chibow.org/, también puede consultarse una red de búsqueda: http://www.gitrace.org/index.html. La primera de estas maternidades-orfanatos se abrió en Noruega en abril de 1942. Ver en NiCHOLAS, L. H., Cruel World: The Children of Europe in the Nazi Web, New York, Knopf, 2005, pp. 274 y ss. 
tregaba a familias de acogida seleccionadas al efecto, con el propósito de que continuaran con su inmersión en el nazismo ${ }^{25}$. Los primeros centros Lebensborn surgieron en Alemania ${ }^{26}$, abriéndose posteriormente otros en Austria (3), Bélgica, Dinamarca (2), Francia (1), Luxemburgo (2), Noruega (9) y Polonia (7) ${ }^{27}$. Noruega resultó ser muy importante para el proyecto debido a la consideración de las mujeres noruegas como racialmente aceptables -al ser descendientes de los vikingos-, por lo que tanto las relaciones de soldados alemanes con ellas como el matrimonio estaban permitidos, aunque sometido a la aprobación final del propio Führer, que podría vetar la celebración del matrimonio ${ }^{28}$. No era ésta una situación generalizada, pues, por ejemplo, solo podían lícitamente entablarse relaciones y contraer matrimonio con aquellas mujeres francesas que reunieran los requisitos raciales establecidos en la Ley, prevaleciendo, en consonancia con el propósito del programa, las características raciales sobre la nacionalidad. Por este motivo, proliferaron los centros Lebensborn en Noruega, creándose hasta nueve sedes del proyecto $^{29}$. En ellas nacieron un número incierto de niños, aunque según el TEDH fueron entre 10.000 y 12.000 los nacidos de padre alemán y madre noruega ${ }^{30}$, de ellos 500 en Lebensborn ${ }^{31}$.

25 Si bien la separación de los niños de sus padres es en sí mismo una crueldad y una vulneración del derecho a vivir en la familia, preferentemente, en la familia biológica salvo que la separación sea precisa en aras al interés superior del menor, no fue éste el mayor de los problemas que debieron sufrir estos niños, pues al finalizar la Guerra comenzaría el peor de los periodos de su existencia.

26 El número de los centros creados en Alemania es incierto, pues si bien HaMmer, J. («Hitler's children», en Newsweek, 3/29/2000, vol. 135, Issue 12, pp. 3/5 de la versión electrónica en http:// www.newsweek.com/hitlers-children-156465) lo eleva hasta los 20, BERGER, K. («Children of the Lebensborn: the Search for Identity in Selected Literary Text of the Berlin republic», en Focus on German Studies, 15, 2008, pp. 104 y ss.) lo reduce hasta las 9, incrementando a 10 las instalaciones de este programa ubicadas en Noruega.

27 Vid. Thiolay, B., Lebensborn. La fabrique des enfants parfaits, Paris, Flammarion, 2012.

28 El matrimonio se permitía con mujeres finlandesas, suecas y danesas, aunque siempre que se obtuviera la preceptiva autorización. WesTERLUND, L., The Children of German Soldiers. Children of Foreign Soldiers in Finland 1941-1948, Helsinki, Painopaikka, Nord Print, 2011, capítulo titulado «Marriages and Engagements in the Light of Racial Doctrine Engagement and marriage announcements between German soldiers and Finnish women in newspapers 1941-44», p. 176 y ss

29 Alderhaug, G., «Memory, Archives and the Public Record», en Archival Science, 2011, 11, pp. 13 y ss, la idea del texto se encuentra en la página 16 .

30 Vid. Decisión de inadmisión en el caso Werner Hermann Thiermann and others v. Norway, supra, p. 3.

31 Valderhaug, G. («Memory, Archives and Justice -a Norwegian perspective», en Comma, International fournal on Archives, 2005-3, pp. 1 y ss) reitera el segmento indicado en el texto (p. 2). El mismo número maneja Grover, S. C., The European Court of Human Rights as a Patbway to Impunity for International Crimes, Berlin, Springer-Verlag, 2010, p. 65. OlSEN, K. «Under the 
Si bien desde una perspectiva de la aplicación del derecho interno del Tercer Reich todos los comportamientos referidos hasta este punto pudieran resultarar perfectamente legales, no ocurre lo mismo con el Derecho Internacional. Nos encontramos aquí con un ejemplo que ilustra a la perfección el modo en el que un ilícito internacional es tal, con independencia de la calificación que ese acto merezca desde la perspectiva interna. Por ello, al finalizar la Segunda Guerra Mundial, el Tribunal de Nuremberg juzgó a Ulrich Greifelt, entre otros motivos, por haber liderado cuatro organizaciones que tenían competencias en materia racial, siendo una de ellas Lebensborn, puesto que había sido el responsable de poner en práctica el programa de germanización, lo que evidencia la ilicitud del proyecto ${ }^{32}$.

El caso de Max Sollman es muy interesante, pues había sido director del Proyecto Lebensborn, se le imputaban los siguientes cargos: «the kidnapping of alien children, taking away infants of Eastern workers, and the plunder of public and private property» ${ }^{33}$. Sin embargo, según el argumento acogido finalmente por el Tribunal, Lebensborn disponía de una serie de centros en los que se cuidaron niños que habían sido previamente secuestrados para procurar su germanización, pero las maternidades-orfanatos se limitaron a prestarles el cuidado preciso y a entregarlos a familias alemanas deseosas de acogerles, lo que motivó su declaración de no culpabilidad por este cargo.

Si bien en los centros de Lebensborn se procuraba asistencia sanitaria y cuidado a los pequeños, resultaba una atención discriminatoria por cuanto solo se atendía a quienes se acomodaban a un perfil étnico muy determinado, pues si los niños, pese a las características de sus progenitores, no se acomodaban a los estándares establecidos al efecto, se destinaban a ser utilizados en experimentos, enviados a campos de trabajo forzado o de exterminio. Este hecho no motivó condena alguna para los procesados por el Tribunal de Nuremberg, al conseguir sus abogados convencer de que la responsabilidad primordial de sus defendidos era el cuidado y crianza de menores, lo que era cierto, pues quien adoptaba las decisiones sobre el destino de los pequeños eran los «inspecto-

care of Lebensborn: Norwegian War Children and their mothers», en ERICSSON, K. Y SIMONSEN E. (eds.), Children of World War II. The Hidden Enemy Legacy, Nueva York, Berg, 2005, pp. 15 y ss. Reduce el dato unos 8.000 en p. 28-29 y 49, lo que evidencia lo incierto del número de niños nacidos de padre alemán durante la época que nos ocupa.

32 Ver el caso $\mathrm{n}^{\circ} 73$, Trial of Ulrich Greifelt and others. United States Military Tribunal, Nuremberg. $10^{\text {th }}$ October, 1947-10 th march, 1948, en: http://www.worldcourts.com/imt/eng/decisions/1948.03.10_ United_States_v_Greifelt2.pdf, p. 1

33 Id. nota anterior, p. 34. 
res», las autoridades de las SS, pero también lo es que, sin la connivencia de las autoridades de estos centros, el resultado podría haberse evitado. Por este motivo, las personas que relacionadas con Lebensborn resultaron condenadas por el Tribunal de Nüremberg, lo fueron tan sólo por pertenencia a organización criminal: Las Schutzstaffel (SS), responsables de estas decisiones ${ }^{34}$.

Además de lo anterior, se impidió a las madres el ejercicio de sus derechos respecto de los hijos alumbrados, lo que transforma la adopción en una privación del niño sin autorización materna reducida a un papel estrictamente reproductor. En todo caso, convengamos que esta separación ya se consideraba contraria a los derechos de los niños, pues en el Informe sobre la situación de los niños polacos bajo la ocupación alemana, se establecía que se había vulnerado el derecho de los niños «à la famille et à une existence stable» ${ }^{35}$. Es evidente que este incumplimiento es atribuible las autoridades alemanas con las separaciones impuestas, así como con los secuestros realizados en el territorio del este europeo, pero las circunstancias en las que tuvieron que sobrevivir estos niños en el periodo de posguerra resultaron de extrema dureza.

Los esfuerzos realizados para procurar, al finalizar la Segunda Guerra Mundial, la reunión entre los niños y las madres, tanto de los que se encontraban en estos centros como los que habían sido adoptados por familias alemanas y cuyo procedimiento de germanización se encontraba en un grado avanzado, fueron infructuosos por dos motivos: 1) debido a la destrucción de los archivos de los centros Lebensborn en los últimos días de la contienda ${ }^{36} ; 2$ ) la filiación falseada en los documentos de nacimiento, pues no solo les cambiaron nombres y apellidos, sino también se introdujeron nombres ficticios para los padres ${ }^{37}$. En el caso de los niños secuestrados en el este europeo, el reencuentro se dificultó aún más, pues a los motivos anteriores se añadió que habían olvidado su lengua materna (como consecuencia de los castigos impuestos cuando utilizaban un idioma distinto del alemán) y carecían de recuerdos que pudieran conducir a identificar su lugar de procedencia.

34 De hecho, Sollman salió de prisión tras la celebración del proceso (concluido el 10 de marzo de 1948), pues se consideró que la condena cubría el tiempo ya transcurrido en la prisión, desde el 6 de julio de 1945.

35 La referencia completa del documento de la UNESCO se encuentra supra.

$36 \mathrm{Al}$ parecer, solo en Noruega se conservaron los archivos de Lebensborn, lo que permitió casos como el de Maroger, K., Les racines du silence, París, Anne Carrière, 1998, quien muchos años después de ser adoptada por una familia francesa, pudo encontrar a su familia biológica en Noruega gracias a la existencia de los archivos en cuestión.

37 Vid. Thiolay, B., supra. 


\section{LAS CONSECUENCIAS DE SER HIJO DEL ENEMIGO EN NORUEGA}

En este punto me referiré a tanto a los hijos de los soldados alemanes con madre noruega conocida, como a aquellos que formaron parte de la disparatada idea que fue Lebensborn. Estos últimos alcanzaron la posguerra con unas carencias afectivas importantes, experiencia a la que se sumó concluida la guerra el estigma de ser hijos del enemigo, de un enemigo que como ocupante había resultado especialmente cruel. Este duro recuerdo repercutió muy negativamente en el trato que se dispensaría a los hijos de los soldados alemanes en las zonas que ocuparon, esos niños fueron las débiles víctimas, en esta ocasión, atribuible a los entonces ocupados, ahora vengadores de aquel dolor. $\mathrm{Mi}$ intención es observar la vigencia de la discriminación que sufren los hijos del enemigo en conflictos más recientes, similares a los problemas que tuvieron que superar aquellos y para los que el Derecho Internacional no aportó solución alguna, con el propósito de extraer enseñanzas para el futuro. Para poder profundizar en las cuestiones que nos interesan, vamos a estructurar este epígrafe refiriéndonos en primer lugar a los hechos y a los derechos conculcados, para después centrarnos en aspectos relacionadas con el procedimiento de admisibilidad ante el TEDH, concluyendo con el análisis de la potencial aplicación al caso de otras normas internacionales.

\section{Los bechos}

En el caso de Noruega, los hijos de padre alemán, con independencia de que provinieran de los centros de Lebensborn ${ }^{38}$ o no, resultaron estigmatizados al final de la contienda, siendo muchos de ellos hijos matrimoniales de mujeres noruegas $^{39}$. Concluida la Segunda Guerra Mundial, las autoridades noruegas

38 En el siglo XXI se han publicado obras que contienen los relatos sobre la situación en la que transcurrió la infancia de los hijos de alemanes, especialmente en Francia. Ver, por ejemplo, PICAPER, J-P.; NoRZ, L., Enfants maudits. Ils sont 200 000, On les appelait les «enfants de Boches», Ginebra, Syrtes, 2004; MARoger, K., Les racines du silence, Paris, Anne Carrière editeur, 2008; VIRGILI, F., Naître ennemi: Les enfants de couples franco-allemands nés pendant la Seconde Guerre mondiale, Paris, Payot, 2014. Sobre las mujeres que tuvieron una pareja alemana durante la Guerra, del mismo autor, France «virile»: Des femmes tondues à la libération, Paris, Payot, 2004; Bourdel, Ph., L'épuration sauvage, París, 2008; Desmarais, J., Femmes tondues France -Libération: Coupables, amoureuses, victims, Quebec, 2011; FrÉTIGNÉ, Ph., La tondue 1944-1947, Paris, Vendémiaire, 2013; FouRnie, P., Présumées coupables, Paris, 2016, entre otros.

39 En http://www.lebensbornnorway.com pueden leerse las experiencias vitales de alrededor de cien personas que tuvieron, en su más tierna infancia, relación con Lebensborn. 
fueron conscientes de que uno de los problemas derivados del odio de la población hacia el antiguo ocupante podría materializarse en las que fueron sus parejas/esposas y especialmente en sus hijos. Para proceder a su evaluación y a la visualización de medidas tendentes a evitar las consecuencias de aquella situación, se creó un Comité, denominado «de los niños de guerra» que realizó un informe en el que se indicaba la conveniencia de adoptar medidas que pudieran favorecer la integración social de estos niños (tuvieran su origen en Lebensborn o en parejas germano-noruegas). En este texto se incorporaban dos ideas muy relevantes para el caso que nos ocupa: la primera, la responsabilidad del Estado noruego sobre estos niños, frente a la propuesta de sus autoridades de enviarlos a Alemania, patria de sus progenitore ${ }^{40}$. La segunda, la necesidad de realizar campañas de información con el propósito de facilitar su integración social en un entorno inicialmente muy hostil, instaurar un programa de educación pública o cualquier otro tipo de medidas que pudieran resultar protectoras de estos pequeños en situación de vulnerabilidad ${ }^{41}$. Sin embargo, el Gobierno noruego no aplicó las recomendaciones formuladas por el Comité, con el argumento de la capacidad de absorción de estos niños y de sus madres en la sociedad y con «same legal position as other children $»^{42}$, lo que orientaba precisamente a actuar en sentido contrario del que defendía y finalmente prosperó.

Desafortunadamente, años después se demostró que la ignorancia noruega de las recomendaciones incorporadas en el citado informe, provocó no solo un

40 OLSEN, K. «Under the care of Lebensborn: Norwegian War Children and their mothers», en Ericsson, K.; SimONSEN, E. (ed.), Children of World War II, op. cit. supra, p. 27. La idea de trasladar a los niños a Alemania fue abandonada, según NilsEN, C. E., Breeding bate: The Story of the Norwegian Lebensborn Children, Tesis del Master of Arts presentada en el Departamento de Historia de la Universidad de Houston en 2013, p. 65, por cuanto en una conferencia internacional celebrada en Zürich en septiembre de 1945 se consideró la propuesta inviable debido al contexto de destrucción en el que se encontraba entonces Alemania, que no proporcionaba las mínimas garantías de confort que merecían estos niños.

41 Información extraída de la Decisión de inadmisión en el caso Werner Hermann Thiermann and others v. Norway, op. cit. supra, pp. 20-21.

42 Esta justificación se encuentra en la Audiencia de 8 de marzo de 2007 en el caso Thiemann and Others v. Noruega ante el TEDH. Aunque, como aprecia GrOvER, S. G., The European Court of Human Rights as a Patbway to Impunity for International Crimes, op. cit. supra, p. 87, ante el Tribunal, el Gobierno no mostró evidencias «of the excellent integration of most war children into Norwegian society and their good life outcomes. Indeed, the 2004 research reports presented to the European Court of Human Rights speak to the opposite being the case. Further, there was no question that the adverse treatment the war children received at least in the early post WWII years was based in part on legislated discrimination.» 
resultado nefasto en la vida de estos menores, sino también la vulneración de todos los derechos imaginables de los que eran titulares. De este resultado solo puede ser responsable el Estado noruego por un comportamiento claramente negligente cuyas consecuencias resultaban previsibles, pese a lo cual se negó a adoptar las medidas preventivas indicadas en el informe. Cuando se advirtieron los efectos nocivos derivados de aquella omisión, tampoco reaccionó reprimiendo los comportamientos vulneradores cuyas víctimas fueron los niños que formaban parte de un grupo de extraordinaria vulnerabilidad en el contexto de la posguerra ${ }^{43}$. Entre los comportamientos de los que fueron víctimas los hijos de soldados alemanes, y que se pusieron de relieve en el procedimiento ante el TEDH se encuentran experiencias de estigmatización y exclusión social, maltrato físico y psicológico, abuso, acoso, negligencia en su cuidado y en su educación, ingreso en instituciones psiquiátricas, pues a todos se les consideró personas con potenciales problemas mentales ${ }^{44}$, debido a la creencia de que:

«only a mentally underdeveloped girl would want to fraternize with the enemy, and only an equally underdeveloped German soldier would be content with a girl like that; consequently, the offspring of such breeding most probably would be undeveloped children $»^{45}$.

Por ello, algunos de estos niños fueron enviados a instituciones mentales, sin haber sido evaluados por especialistas, atendiendo exclusivamente a la nacionalidad paterna ${ }^{46}$. Por otra parte, podríamos pensar que, si bien jurídica-

43 Borgersrud, L., «Meant to be Deported», en Ericsson K. y Simonsen, E. (eds.), Children of the II World War, Bloomsbury, 2005, p. 71 afirma que la mayoría de la población noruega al concluir la Segunda Guerra Mundial estaba convencida de que los niños de Lebensborn y sus madres deberían ser deportados a Alemania en aras a la defensa del mejor interés de la seguridad nacional.

44 Ericsson K. y Ellingsen, D., «Life Stories od Norwegian War Children», en Ericsson K. y Simonsen, E. (eds.), Children of the II World War, op. cit. supra, p. 94 afirman que en «May 1945 editorial in the Lofotposten, a daily newspaper from the Nordland, the autor asserted, «They are unable to become Norwegians Their father were Germans; their mothers were Germans in thought and action... They Will forever constitute an element of irritation und unrest among the pure Norwegian population».

45 OLSEN, K., «Women and Children in the front line: the 'Jerry Girls' $f$ Norway and their Children», en Comma: International fournal on Archives, 2004-1, pp. 95 y ss. De hecho, según cuenta Hammer, J., «Hitler's Children», op. cit. supra, «The head of Norway's largest mental hospital stated that women who had mated with German soldiers were 'mental defectives' and concluded that 80 percent of their progeny must be retarded», pp. $3 / 5$.

46 Según los archivos que se conservan, al terminar la Segunda Guerra Mundial, veintisiete de ellos fueron conducidos primero a un campo de prisioneras en el que se había recluido a algunas mujeres que habían tenido relaciones con soldados alemanes y cuando este fue cerrado, a una ins- 
mente el comportamiento de los vencedores respecto de estos pequeños posee una única lectura, el grado de afectación sobre ellos difería en función del entorno en el que se desarrollara el niño, pues en muchos casos:

«The alleged perpetrators were not always strangers but often persons in the applicant's near environment, such a foster and adoptive parents, step fathers, grandparents, class mates and even school personnel who also tolerated the harassment. A number of the applicants have suffered from psychological problems and are unable to work. There can be no doubt that if a State were to be found liable under the Convention for a large number of people being subjected to such treatment, this would constitute a very serious matter.» ${ }^{47}$

A todo lo anterior hay que añadir el contenido de los informes que se publicaron en 2002, que «suggested the children has been subjected to experiments with LSD in which at least five died $\gg^{48}$. En definitiva, estas actuaciones activas u omisivas resultan atribuibles al Estado, ya sea por haberlas consentido o por no haber adoptado las medidas oportunas para evitar un resultado de marginación y pobreza de las que fueron víctimas los niños afectados. Además de ello, hay evidencias que indican el interés de las autoridades noruegas por trasladar a los hijos de soldados alemanes fuera del territorio nacional. K. Olsen nos ilustra en este punto sobre acerca del intento de enviar, en 1945, unos 9.000 a Australia como mano de obra, que los australianos no aceptaron ${ }^{49}$. Sin embargo, de haber fructificado probablemente algunos de quienes reclamaron ante el TEDH habrían podido disfrutar de un futuro mejor que el que tuvieron en suelo noruego.

titución estatal para «Mentally retarded persons», en palabras de OLSEN, K., id. Nota anterior p. 29. Un total de 2.500 se consideró que no podrían ser buenos ciudadanos y, en consecuencia, irrecuperables. Vid. MAROGER, K., Les racines du silence..., op. cit. supra, p. 125.

47 Decisión de 8 de marzo de 2007, la sala primera del Tribunal Europeo sobre la admisibilidad del asunto Werner Hermann Thiermann..., op. cit. supra, p. 26. También hay documentados casos de estas características en Francia, por ejemplo: Picaper, J-P.; NorZ, L., Enfants maudits, Paris, Editions du Syfles, 2004.

48 IsHeRWOOD, J., «Norway to pay for lost years of war children», noticia publicada en http:// http://www.telegraph.co.uk/news/worldnews/europe/norway/1414838/Norway-to-pay-forlost-years-of-war-children.html

49 OLSEN, K., «Norwegian war children's work for justice - the role of archives», en Comma: International fournal on Archives, vol. 1, n. ${ }^{\circ}$ 2, pp. 47-56. En el mismo sentido se pronuncia VALDERHAUG, G., en «Memory, Archives and Justice -a Norwegian perspective», op. cit. supra, pp. 1 y ss. Aunque eleva la cifra a 12.000 (p. 2). 
Un número mucho menor (treinta) fueron deportados a Suecia para su adopción en el verano de 1945, aunque la legislación noruega impedía la deportación de nacionales ${ }^{50}$, la nacionalidad no fue un problema, ya que en virtud del Decreto especial aprobado en agosto de 1945 para privar a las mujeres casadas con soldados alemanes después de la invasión del 9 de abril de 1940 de esa nacionalidad, evitaron (eso sí, con efectos retroactivos) la transmisión de la nacionalidad de madres a hijos ${ }^{51}$. De este modo se cumplían las prescripciones legales puesto que no se deportaban nacionales, sino hijos de soldados alemanes, y así se les contemplaba en el imaginario colectivo, con la idea subyacente de que se les dispensaba el trato que probablemente merecían los soldados del ejército enemigo, al que nunca habían pertenecido estos menores. Según Nilsen, estos niños no pudieron ser noruegos de pleno derecho hasta $1964^{52}$.

Los hechos antes indicados podrían ubicarnos en el supuesto del artículo 2.d) de la Convención de 1948 para la prevención y sanción del delito de genocidio. Afirmación que resulta más que cuestionable pues para ello debería probarse la presencia del propósito inescindible del concepto del tipo, que no es otro que el de «destruir total o parcialmente a un grupo nacional, étnico, racial o religioso». Si bien el número reducido de los deportados no parece evidenciar esta finalidad, también hemos de tener en cuenta la hipótesis de que el afán destructor existiese, pero no por las razones que se indican a continuación (en el mismo precepto), puesto que la mayoría de los niños compartían la nacionalidad materna hasta la entrada en vigor de las normas que les privaban de ellas, sin que formaran parte de un grupo racial, étnico o religioso diferente.

Tras los infructuosos planes antes referidos, como consecuencia de la modificación social producida en Noruega en 1947, se creó un sistema que proporcionó a los niños mensualmente unos beneficios estatales, de los que quedaron al margen aquellos que carecían de la nacionalidad noruega y quie-

50 Valderhaug, G., «Memory, Archives and the Public Record...», op. cit. supra, pp. 13 y ss, afirma que las autoridades noruegas contactaron con algunos Estados europeos con intención de lograr un acuerdo para «intended solve their 'war child problem'»(p. 14).

51 Valderhaug, G., id. Nota anterior, p. 13 y ss, la transcripción del texto se encuentra en la página 14 y las ideas que se vierten son de la p. 15. GROvER, S. G., op. cit. supra, p. 86 afirma que la norma que privaba a los hijos de soldados alemanes de la nacionalidad fue modificada el 1 de enero de 1949, permitiendo la nacionalidad noruega a hijos nacidos de madres noruegas y padres alemanes, aunque paradójica e incomprensiblemente, las madres (que eran las transmisoras de la nacionalidad) no podrían recuperarla aunque vivieran en Noruega. Un año después se deroga la norma anterior para permitir la recuperación de la nacionalidad por las madres y los hijos, estos últimos a partir de los 18 años o por decisión del gobierno.

52 Vid. NiLSEN, C.E., op. cit. supra, p. 70. 
nes no vivían con sus madres ${ }^{53}$. En consecuencia, los hijos de matrimonios entre noruega y alemán y los niños de Lebensborn. Exclusión que se mantuvo años después de finalizada la Guerra, pues según S. Grover:

«continued until the Bread Winner Insurance Act and Advance Payment Act came into force on 1 April 1958 and allowed the war children who had previously been excluded to then receive the benefits» ${ }^{54}$.

Esto nos sirve para confirmar que la discriminación de la que fueron objeto estos niños se mantuvo más allá de 1953, fecha a partir de la cual Noruega estaba obligada al cumplimiento del Convenio Europeo, lo que fundamenta la naturaleza de hecho continuado de la vulneración de los derechos contemplados en el Tratado de referencia. A la vista de lo anterior, resulta evidente la atribución a Noruega de la marginación de estos niños, hijos de soldados alemanes puesto que, conocida su situación se veían excluidos de beneficios que les correspondían atendiendo a la nacionalidad de sus progenitores (en este caso, materna).

La situación sufrida por estos niños ha sido conocida sesenta años después de concluir la Segunda Guerra Mundial, cuando el TEDH se pronunció acerca de una demanda introducida por las víctimas de Lebensborn contra Noruega por la discriminación sufrida y sus consecuencias. Las heridas aún no han cicatrizado y encontramos buena muestra de ello en, por una parte, la infructuosa demanda recién mencionada, por otra, que cuando han transcurrido más de setenta años de la finalización de aquella contienda se siguen publicando trabajos sobre estas cuestiones, que solo comenzaron a ver la luz en los últimos años del siglo XX; y, por último, las autoridades noruegas pidieron disculpas por la discriminación de la que habían sido objeto este numeroso grupo de niños en la intervención de Año Nuevo del Primer Ministro, el 1 de enero de $2000^{55}$. Sin embargo, las excusas a las mujeres que tuvieron relaciones sentimentales con los soldados alemanes durante la Segunda Guerra Mundial tardarían aún trece años en llegar, pues ha sido el 16 de octubre de 2018 cuando la Primera Ministra se ha disculpado con las mujeres que tuvieron que sufrir una dura posguerra al considerarlas colaboracionistas por haber

53 Valderhaug, G., ibid., p. 16.

54 Vid. Grover, S. G., op. cit. supra, p. 87.

55 Vid. Decisión de inadmisión del TEDH en el asunto Werner Hermann Thiermann and Others against Norway, op. cit. supra, p. 4. 
mantenido relaciones con los soldados alemanes ${ }^{56}$. Palabras que llegaron con demasiado retraso, en un momento en el que quedan pocas agraviadas que puedan escucharlas.

\section{Los derechos}

Que se vulneraron los derechos de los niños y de sus madres es evidente. En todos los países que fueron ocupados, la misógina reacción popular contra las mujeres que habían tenido relaciones con los soldados ocupantes fueron incontrolables, aunque en ocasiones, se hicieron llamadas institucionales a la calma $^{57}$, lo que no ocurrió en el caso que nos ocupa, donde además, la situación continuó en el tiempo. El motivo de la situación por la que debieron atravesar los pequeños fue solo su origen paterno, a quien la mayoría de ellos no conoció y sólo identificaron el motivo de su marginación cuando fueron adultos.

Por otra parte, si bien es cierto que al finalizar la Segunda Guerra Mundial no existía el nivel de protección internacional de Derechos humanos del que gozamos en la actualidad y no se había adoptado la Convención de Naciones Unidas sobre los derechos del niño, no lo es menos que este texto concreta la aplicación de los Derechos Humanos a los menores de edad, por cuanto sus derechos existen desde el mismo momento en el que existe aquel corpus iuris. El hecho de que hubiera una reunión internacional ${ }^{58}$ en la que se discutiera el futuro de estos niños puede leerse como una prueba más de la existencia de la convicción de la existencia de aquellos.

Además, podemos utilizar como fundamento de la afirmación de la vulneración de estos derechos los dos informes realizado por la UNESCO en 1948: uno relativo a los problemas de los niños víctimas de la guerra; y, otro, sobre la situación de los niños polacos bajo la ocupación alemana ${ }^{59}$. Leyendo

56 https://www.elmundo.es/internacional/2018/10/19/5bc8b79a22601d28798b4578.html. Las mujeres fueron castigadas por una evidente cuestión de género, con sanciones más duras que otras categorías de colaboracionistas, aunque no ayudaron en modo alguno -como ha reconocido recientemente la Presidenta del Gobierno noruego- al logro de objetivos militares.

57 https://www.theguardian.com/lifeandstyle/2009/jun/05/women-victims-d-day-landings-second-world-war

58 Conferencia celebrada en Zurich en septiembre de 1945, de la que da cuenta NiLSEN, C.E. en su tesis doctoral, Breeding hate: The Story of Norwegian Lebensborn Children, op. cit. supra, p. 65.

59 El primero es el Informe preliminar realizado por el Doctor Simone Marcus publicado el 5 de noviembre de 1947. Documento Educ./55; el segundo es Fruto de la reunión de directores de pueblos de niños, producida entre los días 4 y 11 de julio de 1948. El documento en cuestión 
el contenido de ambos podemos aplicar sus afirmaciones a los hijos de los soldados alemanes en Noruega. Así, en el Informe indicado en último lugar se proclamaba la vulneración del derecho a la educación por parte del régimen nazi impuesto tras la ocupación de Polonia por no permitir a los niños que no fueran «de race allemande ${ }^{60}$ superar cuarto curso de primaria, impartiendo un nivel de formación muy bajo. Evidentemente, las autoridades noruegas al internar a estos niños en instituciones psiquiátricas por considerarlos deficientes mentales solo por el hecho de ser hijos de padre alemán (lo que no ocurría con los hijos de madre alemana y padre noruego), vulneraron no solo este derecho, sino también el derecho a un desarrollo psíquico adecuado, lo que inevitablemente es la base para la adquisición de una formación adecuada que los pudiera preparar para el futuro.

El derecho a la educación que también resulta vulnerado para los niños que, habiendo nacido en Noruega, habían superado las primeras fases del proceso de nazificación y habían sido enviados en acogida o adopción a familias alemanas que pudieran continuar su formación. Concluida la contienda, esos niños fueron repatriados a Noruega, cuyo idioma desconocían pues el único que habían escuchado era el alemán, lo que dificultó evidentemente su educación, impartida en noruego exclusivamente y sin apoyo alguno y también su socialización. El procedimiento de desgermanización provocó problemas relevantes para su presente, pero muy especialmente para su futuro ${ }^{61}$.

El derecho a una familia y a una existencia estable ${ }^{62}$ es otro de los derechos que la UNESCO considera vulnerado por el Tercer Reich, en unos términos que resultan claramente aplicables al supuesto noruego. Es cierto que en el caso alemán era consecuencia de las evacuaciones de población producidas en Polonia, en las que se habían provocado huérfanos con la consiguiente privación de un entorno familiar. En el supuesto noruego, el origen de esa orfandad sustantiva fue la ausencia del único progenitor que podría ser próximo: la madre, como consecuencia del internamiento producido como

se publicó el 28 de julio de 1948, es UNESCO/ED/Conf.1/18. Poco después, la misma organización publicaba L'enfance victime de la guerre. Un étude de la situation européenne, par le Docteur Thérèse Brosse, UNESCO, Paris, 1950, que puede leerse en: http://unesdoc.unesco.org/ images/0013/001337/133701fo.pdf, se trata de un estudio constructivo sobre la situación de los niños que han sufrido la guerra y los posibles remedios para mitigar las consecuencias de la atroz experiencia.

60 Id. nota anterior, p. 2.

61 NiLSEN, C.E., op. cit. supra, p. 68.

62 Vid. el informe citado supra sobre los niños polacos, p. 4. 
consecuencia de su consideración como colaboracionista del ocupante, en aquellos supuestos en los que no fueron los niños los ingresados en las instituciones antes indicadas. Esto nos conduce a un punto anterior, el de los efectos psicológicos derivados de la guerra, que resulta igualmente aplicable a este supuesto, al afirmar que

«La guerre a disloqué la famille, cellule nurricière de l'enfant et garant de son equilibre affectif... les parents ne pouvaient plus apporteer aux enfants qu'un mínimum d'affection et de présence, une part infime de l'éducation, des conseils et des soins qu'ils exigeaient $\gg^{63}$.

Condiciones en las que «... les enfants se sont trouvées en fase d'une réalité très rude, sans moyens de défense ni frein» ${ }^{64}$, lo que conduce a una dificultad de adaptación a la vida normal. Reflexiones que resultan aplicables a los niños que nos ocupan, aunque la privación del entorno familiar no solo se produjera para algunos durante la guerra (en el caso de los niños de Lebensborn) sino también y muy especialmente durante la larga y complicada posguerra. En todo caso, los daños psicológicos afectan a la capacidad de socialización y provocan dificultades para forjar la personalidad, lo que repercute no solo en su presente, sino también y muy especialmente en su futuro, en la medida en que dificulta de un modo importante la adquisición de herramientas para el ejercicio de una profesión. Este efecto se evidencia en la Decisión de inadmisión del TEDH, en la que se indica que los siete demandantes que pasaron por Lebensborn cuentan con una prestación por discapacidad y, uno de los informes aportados, justifica la situación actual en su «traumatic childhood» ${ }^{65}$. No es de extrañar que, a la luz de estas experiencias, de acuerdo con I.C. Mochmann y $\mathrm{S}$. Lee los hijos noruegos de padres alemanes «have poorer health, higher suicide rates, lower levels of education and lower income tan other Norwegians from the same age cohort. ${ }^{66}$

La privación del derecho a la nacionalidad es otra de las consecuencias de la política noruega hacia estos niños. La Declaración Universal de Derechos

63 La frase se encuentra en el Capítulo segundo del Informe sobre los problemas de los niños víctimas de guerra, del Dr. Simone Marcus, de 5 de noviembre de 1947, citado supra, p. 9.

64 Id. nota anterior.

$65 \mathrm{Vid}$. página 6 de la Decisión citada supra.

66 Mochmann, I.C.; LeE, S., «The Human Rights of Children Born of War: case analyses of Past and present conflicts», en Historical Social Research, 35, 2010, 3, pp. 268 y ss. La frase transcrita en el texto se encuentra en la página 276. 
Humanos establece (art. 15) este derecho que la Convención sobre los derechos del niño concreta en estos titulares (art. 7.1). La eficacia del derecho a la nacionalidad es esencial para la efectiva protección y garantía del resto de los derechos humanos, no solo de los niños, pero de éstos también. Estos niños deberían tener garantizada la nacionalidad de la madre sin ningún prejuicio como establece la Convención, incluso la del padre, por muy enemigo que fuera, no debería privársele de la posibilidad de decidir su adquisición. Esto podría facilitar una eventual reclamación de manutención y compensación.

En el nazismo se calcula que se enviaron más de 200.000 niños polacos a centros del Proyecto Lebensborn para ser germanizados, perdiendo así su nacionalidad ${ }^{67}$. Los niños noruegos dejaron de serlo porque a sus madres se les privó de su nacionalidad, lo que les impedía transmitírsela a sus hijos, con lo que la crueldad de la privación de este vínculo resulta, cuando menos, igual de grave en ambos supuestos, dado que con ello se les impediría disfrutar de algunos beneficios que sí tenían el resto de los niños del país, como vimos antes, condenándoles a la pobreza. Esto ha de añadirse a la falta de apoyo económico de la familia paterna, como se indica en la Decisión de inadmisión del TEDH, pues:

«For political reasons, Norwegian authorities did not wand the unmarried mothers to be in touch with their children's fathers, and all legal proceedings to establish paternity -about 6.000 cases- were halted in 1946 . When these cases were re-opened in 1950, only a small portion of the mothers reestablished their claims and less than 500 fathers ended up paying ${ }^{88}$,

Lo que nos conduce a afirmar una discriminación económica, puesto que, por una parte, el Estado no permitió a los hijos de soldados alemanes beneficiarse de las ayudas estatales al habérseles privado de la nacionalidad noruega que era un requisito para ello (o convivir con sus madres), y por otra, se impidió que las familias de esos progenitores sufragaran los gastos de los menores en cuestión. El resultado es el indicado en el párrafo anterior: la pobreza. Lo que nos recuerda inevitablemente a la Sentencia de la

67 Vid. Informe de la UNESCO citado supra, p. 7.

68 Valderhaug, G., en «Memory, Archives and the Public Record...», op. cit. supra, pp. 13 y ss, la transcripción del texto se encuentra en la página 16 e indica que la idea se encuentra en la obra de Borgersrud, L., Vi Ville ikke ha dem, Scandinavian Academic Press, Oslo, 2005, pp. $363-$ 364. 
Corte Interamericana de Derechos Humanos, en el caso de los «niños de la calle ${ }^{69}$, en la que se afirma que el Estado que tolera en su territorio la violencia sistemática contra los niños que se encuentren en una situación de riesgo comete una doble violación: por una parte, por permitir que vivan en una situación de miseria (es cierto que se refiere a los niños de la calle, pero su reflexión resulta aplicable aquí, pues las medidas adoptadas impulsan a estos pequeños a la pobreza), impidiéndoles desarrollarse correctamente; en segundo término, vulneran su derecho a la salud e incluso el derecho a la vida por el riesgo en el que les ubica la ausencia de adopción de medidas necesarias para prevenir y reprimir estas situaciones y abusos. Conclusión sustantiva que resulta predicable del supuesto que nos ocupa, aunque estos niños (afortunadamente) no tuvieran que vivir en la calle.

Las medidas anteriores nos conducen a una breve reflexión sobre el principio de no discriminación que, recordemos, se encuentra en la base de los Derechos humanos. En este sentido, es evidente su prohibición también en lo que se refiere a los menores ${ }^{70}$, por ello no es de extrañar que el Pacto Internacional de Derechos civiles y políticos incorpore la siguiente redacción en lo que se refiere a los menores de edad:

«Todo niño, sin discriminación alguna por motivos de raza, color, sexo, idioma, religión, origen nacional o social, posición económica o nacimiento, tiene derecho a las medidas de protección que su condición de menor requiere, tanto por parte de su familia como de la sociedad y del Estado.»

Esta redacción supone una protección reforzada respecto de la que podemos ser destinatarios los adultos, al unirse el artículo 24 recién citado a los artículos 2 y 26 del Pacto, que proclama con carácter general el principio que nos ocupa (el último de ellos concretado en su igualdad ante la ley). Sin embargo, si la situación que originó el tratamiento diferenciado de los hijos de soldados alemanes en el Segunda Guerra Mundial se produjera en estos momentos, la observación general de este Comité no garantizaría necesariamente un mejor tratamiento que el prestado por parte de la familia o de la sociedad

69 Vid. Sentencia de la Corte Interamericana de Derechos Humanos de 19 de noviembre de 1999, en http://www.corteidh.or.cr/docs/casos/articulos/seriec_63_esp. pdf

70 En este sentido véase la Observación general $n^{\circ} 18$ sobre la No discriminación aprobada en el $37^{\circ}$ periodo de sesiones (1989) por el Comité de Derechos Humanos, en: http://tbinternet. ohchr.org/_layouts/treatybodyexternal/Download.aspx?symbolno=INT\%2 fCCPR \% 2fGEC\% $2 \mathrm{f} 6622 \&$ Lang $=$ en 
en la que vive, pero sí por parte del Estado, obligado a no discriminar por razones de origen nacional, que es precisamente la fuente de estigmatización en el caso en presencia. Cuestión distinta es averiguar cuáles son las medidas de protección imprescindibles que establece el Pacto, cuya identificación, según el propio Comité afirmaba en 1989, es competencia estatal «en función de las exigencias de protección de los niños que se encuentran en su territorio al amparo de su jurisdicción ${ }^{71}$. Evidentemente, puesto que han de adaptarse a las necesidades de los niños en cuestión, podrán pertenecer a un amplio espectro, sin que su modalidad esté predeterminada, pudiendo ser económicas, culturales, sociales... ${ }^{72}$

Probablemente, desde una perspectiva sociológica o psicológica pudiera comprenderse la reacción frente a los hijos del enemigo por parte de aquellos que sufrieron su ocupación, pero jurídicamente carece de justificación algu$\mathrm{na}^{73}$. En todo caso, las autoridades estatales no deberían haberse dejado llevar por estos sentimientos, pues tenían la obligación de proteger los derechos humanos de toda su población, y dado que aceptaron no enviar a Alemania a este nutrido grupo de niños, lugar en el que probablemente habrían tenido una vida más acomodada a la edad que les tocaba vivir, a pesar del contexto de posguerra en el que se encontraba Alemania, se habían responsabilizado de garantizar el bienestar de los pequeños.

Por su parte, los demandantes ante el TEDH relataron la estigmatización social que sufrieron y de la que es responsable el Estado en la medida en que las autoridades estatales las toleraron y, en algunos casos, incluso los con-

71 Vid. La Obervación general ${ }^{\circ} 17$ sobre los derechos del niño ${ }^{\circ} 17$, aprobada en el $35^{\circ}$ periodo de sesiones (1989) por el Comité de Derechos Humanos, en https://tbinternet.ohchr.org/_layouts/ treatybodyexternal/Download.aspx?symbolno=INT\%2fCCPR\%2fGEC\% 2f6623\&Lang=es

72 Catorce años después de esta Observación, el Comité sobre los derechos del niño de Naciones Unidas, aprobó una Observación general (la quinta) sobre las medidas generales de aplicación de la Convención sobre los derechos del niño. En ella, de nuevo, el Comité reiteraba su incapacidad para «prescribir en detalle las medidas que cada Estado parte considerará apropiadas para garantizar la aplicación efectiva de la Convención», resultando competencia de los Estados parte identificar las medidas apropiadas en cada caso. Ver la Observación General n ${ }^{\circ} 5$ (2003), sobre Medidas generales de aplicación de la Convención sobre los Derechos del Niño (arts. 4 y 42 y párrafo 6 del artículo 44). Doc: CRC/GC/2003/5, de 27 de noviembre de 2003. El texto transcrito se encuentra en el parágrafo 26.

73 Según BeEvor, A., en el caso francés «many of the tondeurs, the head-shavers, were not members of the resistance. Quite a few had been petty collaborators themselves, and sought to divert attention from their own lack of resistance credentials», en https://www.theguardian.com/lifeandstyle/2009/jun/05/women-victims-d-day-landings-second-world-war Reflexión que para el rechazo popular y las acciones de la población resultan extrapolabes a Noruega. 
sideraron de deficientes mentales o se modificó su nombre ${ }^{74}$, con el propósito de desgermanizarlos. En este sentido, las víctimas alegan que el Estado noruego, con su comportamiento, había vulnerado los derechos civiles y políticos que se había comprometido a garantizar en 1953 en virtud de su manifestación del consentimiento a la Convención Europea de Derechos Humano, de forma más del derecho a la vida privada y familiar (art. 8 de la Convención de 1950), no discriminación (art. 14) y vulneración de la prohibición de tratamientos inhumanos o degradantes (art.3), violaciones atribuibles a Noruega debido a la falta de adopción de medidas necesarias para evitar que estos resultados se produjeran.

\section{El procedimiento de admisibilidad ante el TEDH}

Hemos de comenzar considerando que Noruega es miembro de las $\mathrm{Na}-$ ciones Unidas desde noviembre de $1945^{75}$ y que ratificó el Convenio Europeo de Derechos Humanos el 15 de enero de 1952, estando jurídicamente obligado por este tratado desde su entrada en vigor en septiembre de $1953^{76}$. Antes de esta fecha existía la Declaración Universal de Derechos Humanos (cuyos artículos 1,16 y 15.2 se vulneraron con la situación en presencia) y desde 1959 la Declaración sobre los derechos del niño ${ }^{77}$ que, aunque no son tratados internacionales su contenido es muy relevante jurídicamente.

Convengamos, por otra parte, que, si los niños nacieron a partir de 1940, continuaban siendo menores de edad cuando se adoptó la Declaración Universal de Derechos Humanos, así como en el momento de entrada en vigor

74 Con todo lo que ello comporta, pues el Comité de Derechos Humanos en el parágrafo 7 de la Observación General n ${ }^{\circ} 17$ (citada supra) ha afirmado en relación al derecho al nombre del niño establecido en el artículo 24.2 del Pacto que «debe interpretarse que esta disposición está estrechamente vinculada a la que prevé el derecho a medidas especiales de protección y tiene por objeto favorecer el reconocimiento de la personalidad jurídica del niño.» En consecuencia, el cambio de la identidad producida de este modo podría ser susceptible de vulnerar esa personalidad jurídica.

75 Desde el 27 de noviembre de 1945, según se refiere en la página de Naciones Unidas: http:// www.un.org/es/member-states/index.html

76 Aunque Noruega es parte del Convenio Europeo desde 1953, solo adopta una Ley para incorporar su contenido al ordenamiento interno en 1999. Vid. página 11 de la Decisión de inadmisión. Sin embargo, esta apreciación en nada cambia el cumplimiento o no por parte de Noruega de las obligaciones internacionalmente asumidas desde la entrada en vigor del Convenio.

77 La Asamblea General de Naciones Unidas aprobó la Resolución 1386, que la contenía, sin votación, el 20 de noviembre de 1959. 
del Convenio Europeo para Noruega y que los comportamientos producidos contra estos niños no solo vulneran los derechos de los niños sino la categoría general de los Derechos Humanos. En la medida en que los hechos discriminatorios continuaron produciéndose en un momento posterior a esta vigencia, nos encontramos con una vulneración de las disposiciones de este Tratado Internacional, como consecuencia de un delito continuado, pues aunque algunas de las acciones y omisiones vulneradoras referidas se produjeran antes de 1953, fecha de la entrada en vigor del Convenio para Noruega, otros se mantuvieron con posterioridad a aquella fecha, por lo que cabe sostener la aplicación de la categoría recién indicada. Por otra parte, el hecho de que los incumplimientos consumados con anterioridad a la vigencia del Convenio Europeo en Noruega no sean fiscalizables por el TEDH, no impide la consideración de sus hechos como ilícitos atribuibles al Estado en cuestión.

En este punto vamos a centrarnos en dos aspectos puestos de relieve por la Decisión de inadmisión del TEDH: en primer lugar, la prescripción y la reparación; y, posteriormente, la doctrina del margen de apreciación nacional.

\subsection{Prescripción y reparación}

El debate que debía haberse producido al finalizar la contienda tuvo lugar muchos años después, a partir de la década de los noventa, cuando por primera vez se escuchan las acusaciones de maltrato por parte de los entonces niños, víctimas de la estigmatización cuando no auspiciada, tolerada por el Estado. Como consecuencia de ello, en 2001 se presentan unas demandas de indemnización con fundamento en estos hechos ante los tribunales noruegos, que fueron rechazadas por tardías, dado que encontraban su base jurídica en la Ley de 1969 sobre reparación de daños y del artículo 9 de la Ley de 1979 sobre la prescripción, que establecía un plazo de veinte años, sobradamente cumplidos. Posteriormente, esta decisión resultó confirmada por el Tribunal de apelaciones por unanimidad. Fue entonces cuando decidieron acudir al TEDH que declaró inadmisible la demanda como consecuencia de la falta de agotamiento de los recursos internos del Estado infractor, establecido en el artículo 35.1 del Convenio con carácter general y por considerar que el periodo de prescripción establecido por la Ley no podía considerarse arbitrario.

Los demandantes utilizan dos tipos de argumentos para justificar la tardanza de las acciones emprendidas: en primer lugar, uno sin consistencia jurídica, cual es el respeto a las madres, hasta que no fallecieron muchas de ellas 
no consideraron oportuno iniciar el procedimiento con afán protector de sus progenitoras que habían sufrido en su momento las consecuencias de haber tenido un hijo con un padre alemán; en segundo término, y más convincente que el anterior para la perspectiva que nos interesa es la imposibilidad de acceder a informes que solo fueron publicados entre 1999 y 2004 . Este es un dato especialmente relevante, dado que es en estos informes en los que encontraban fundamento sus demandas, que sólo contaron con base documental desde el momento en que cuentan con acceso a la información publicada tardíamente ${ }^{78}$. Había que añadir a ello que en 1986 se adoptó en Noruega una legislación que permitía a los hijos adoptados conocer quiénes fueron sus padres biológicos, y se calcula que alrededor de 1.500 niños de la guerra lo hicieron, algunos de ellos se encontraron con una realidad desconocida: Lebensborn. Fue entonces, cuando se constituyó la Asociación noruega de niños de la guerra solicitando reparaciones por los daños sufridos ${ }^{79}$.

En este sentido podemos plantearnos si nos encontramos ante una situación, que de conformidad con el artículo 15 del Proyecto de artículos de la CDI sobre protección diplomática, excluiría el requisito del agotamiento de recursos internos, con lo cual no cabría la inadmisión por este motivo ${ }^{80}$. Ello es así por cuanto, la situación nos ubica ante un escenario en el que, de haber iniciado el procedimiento de reclamación de conformidad con lo establecido por la Ley, difícilmente se hubiera alcanzado un resultado positivo debido a la inexistencia del fundamento documental preciso, por lo que los recursos internos, en realidad no ofrecían «ninguna posibilidad razonable de obtener esa reparación» (apartado a). Es cierto que existían recursos, pero adolecerían de falta de eficacia debido precisamente a la ausencia sustantiva antes apuntada.

En todo caso, recordemos que no todos los demandantes noruegos encontraban sus orígenes en el proyecto Lebensborn (sólo siete están identificados como tales, en relación con los restantes no se indican los orígenes), algunos eran hijos de parejas germano-noruegas, que fueron entregados en adopción

78 Información extraída de la página 23 de la Decisión de inadmisión en el caso Werner Hermann Thiermann, op. cit. supra.

79 Valderhaug, G., «Memory, Archives and the Public Record», en Archival Science, 2011, 11, pp. 13 y ss, la idea del texto se encuentra en la página 18.

80 Es cierto el Proyecto se refiere al agotamiento de los recursos internos como requisito de ejercicio de la protección diplomática, pero cabría extender la consideración aquí al ser aquel requisito de admisibilidad de las demandas dirigidas la TEDH, de acuerdo con en el artículo 35.1 del Convenio Europeo de Derechos Humanos. 
como consecuencia de que la marginación a la que sometió a sus madres le impidió vivir con sus hijos en un afán de proteger a los pequeños de la doble discriminación de la que serían víctimas. En todo caso, los tribunales noruegos lejos de negar la existencia de aquellas discriminaciones que fundamentan las demandas de los niños de la guerra, reconocen su existencia del siguiente modo: «They concern different forms of violation - passivity on the part of the Government, statements from public individual, serious crimes such as rape, and harassment by private individuals ${ }^{81}$.

A pesar de lo anterior, los tribunales nacionales fundamentan la inadmisión de la demanda en la ausencia de una vulneración continuada en el tiempo de sus derechos, al considerar producidos aquellos hechos antes de 1953, por lo que habrían transcurrido cincuenta y cinco años entre los hechos y el depósito de la demanda ante los tribunales nacionales. En segundo término, cada demandante precisaba probar que había sido víctima de la violación alegada y continuar siéndolo desde septiembre de este año, fecha a partir de la cual Noruega estaba obligado al cumplimiento de la Convención, sabedores de la mermada capacidad probatoria de los demandantes. Inadmitida su reclamación, los afectados recurrieron ante la Oslo City Court, que resolvió del mismo modo y por los mismos motivos que el tribunal anterior, a pesar de lo cual (en respuesta a la solicitud de declaración por parte de los demandantes) los datos manejados «evidence that Norwegian war children had been treated more harshly tan were war children in other European countries in the porst-World War II period required research and was not available to the Court» ${ }^{82}$.

Como consecuencia del debate abierto en los años noventa sobre la cuestión que nos ocupa, se adoptó un White Paper que proponía un sistema de compensación para las personas que hubieran sido víctimas de estos hechos, cuya cuantía se hacía depender de la documentación que pudieran aportar ${ }^{83}$, entre 20.000 y 200.000 coronas noruegas $^{84}$, aproximadamente entre $2.263,20 €$ y 22.632€). Según las estadísticas, la mayoría de las reclamaciones se saldaron

81 Esta trascripción es de la argumentación de la City Court, y figura en la página 8 de la Decisión de inadmisión en el caso Werner Hermann Thiermann and others v. Norway..., op. cit. supra.

82 Grover, S.G., The European Court of Human Rights as a Patbway to Impunity for International Crimes, Springer-Verlag, Berlin, 2010, p. 67-68.

83 Valderhaug, G., «Memory, Archives and Justice -a Norwegian perspective...», op. cit. supra, pp. 1 y ss. La idea del texto se encuentra en la p. 2.

84 Vid. Decisión de inadmisión del TEDH en el asunto Werner Hermann Thiermann and others..., citada supra, p. 17. 
con la cantidad mínima ${ }^{85}$, debido a la ausencia de documentación acreditativa de las burlas de los niños o de las discriminaciones en la sociedad o en la escuela son imposibles de recabar.

A pesar de lo anterior, las autoridades noruegas no pidieron disculpas por la discriminación de la que habían sido objeto este numeroso grupo de niños hasta la intervención de Año Nuevo del Primer Ministro, el 1 de enero de $2000^{86}$. Con esta satisfacción (es evidente que no cabe otra forma de reparación, dado que el daño producido no tiene compensación posible), se reconocía la responsabilidad estatal en la dura situación con la que debieron convivir estas personas por el solo hecho de ser hijos del enemigo. El sistema de compensación fue revisado en 2005 para admitir

«additional grounds (bullying) all of which demostrates that the society was still coming to terms with the consequences of the government's treatment of the war children which had originated in events that occurred many decades previous in post WWII Norway» ${ }^{87}$.

Además, como consecuencia de esta modificación también se facilita el trámite de la obtención de la indemnización, ya que deja de exigirse una prueba documental de los daños sufridos, sirviendo a efectos probatorios una declaración personal creíble.

La existencia de este sistema de compensación concebido para las reclamaciones de los niños de la guerra evidencia que son unas compensaciones específicas por unos hechos distintos, que han de computarse debido a la especificidad con criterios diferentes de la responsabilidad patrimonial del Estado con carácter general. En el supuesto que nos ocupa nos encontramos ante un funcionamiento de la administración noruega no sólo anormal, sino contraria a los derechos humanos de los más vulnerables: los niños, en el que se identifica intencionalidad en unos casos y negligencia en otros. La responsabilidad patrimonial del Estado, tal y como se encuentra configurada en el derecho español es una responsabilidad directa de la Administración, que responde así por los hechos cometidos por sus agentes y, ciertamente, no todos los com-

85 Valderhaug, G., «Memory, Archives and the Public Record», op. cit. supra, p. 18.

86 Vid. Decisión de inadmisión del TEDH en el asunto Werner Hermann Thiermann and others..., op. cit. supra, p. 4.

87 Grover, S.G., The European Court of Human Rights as a Pathway to Impunity for International Crimes, Berlin, Springer-Verlag, 2010, p. 81. 
portamientos ocurridos en relación a estos niños son atribuibles de este modo, aunque podemos pensar lo contrario si partimos de la convicción de que si se hubieran puesto en práctica las prescripciones del informe del comité de 1945 podrían haberse evitado, o cuando menos, disminuido.

Así, S. Grover afirma en este punto:

«However, this relegation of the case to the category of a normal compensation case is not consistent with the Norwegian law which set up the ex gratia system that handles war child claims for compensation as a special category of claim. Hence, the European Court of Human Rights arguably had no basis in law for the deference it showed the Norwegian courts in regarding Theimann as a time barred regular run-of-the-mill tort civil case since Norwegian law itself allows for special treatment of war child cases ${ }^{88}$.

Es cierto que la situación no solo ha de observarse desde el punto de vista de los derechos del niño, sino de los Derechos Humanos en general, pues una vez alcanzada la mayoría de edad la situación no cambió por ello.

\subsection{La doctrina del margen de apreciación nacional}

Del relato precedente se desprende una relación de derechos vulnerados a los hijos de los soldados alemanes en Noruega, entre otros: discriminación, tratos inhumanos o degradantes, privación de nacionalidad, o tutela judicial efectiva... En este punto, debemos recordar a S. Greer ${ }^{89}$ y la diferenciación que realiza entre una distinción de trato y una discriminación, que resulta muy relevante por cuanto la primera sería acorde al Convenio Europeo mientras la segunda se encuentra prohibida por el artículo 14 del mismo texto. Esto nos conduce a la denominada doctrina del margen de apreciación nacional ${ }^{90}$, cuya relevancia deriva de la mención realizada por el TEDH como una justificación de la inexistencia de incumplimiento del Convenio europeo por parte de Noruega.

88 Grover, S.G., id. nota anterior, p. 89.

89 GREER, S., Le marge d'appreciation: interprétation et pouvoir discrétionnaire dans le cadre de la Convention Européenne des Droits de l'Homme, Editions du Conseil de l'Europe, 2000, pp. 7 y ss.

90 Pascual Vives, F.J., «El margen de apreciación nacional en los tribunales regionales de Derechos Humanos: una aproximación contextualista», en Anuario Español de Derecho Internacional, vol. 29, 2013, pp. 2017 y ss. Afirma (p. 225) que nos encontramos ante un «concepto jurídicamente indeterminado», que «No puede considerarse, creemos, como una verdadera doctrina de carácter jurisprudencial». 
Aunque en la Decisión de inadmisión el TEDH realiza una única mención al margen de apreciación nacional, ésta resulta sustantiva, al afirmar que:

«The Court, for its part, having regard to the case as a whole and to its own case-law relating to the right of access to a court in personal injury cases (see, in particular, Stubbings and Others v. the United Kingdom, cited above, $\$ \$$ 50-57), is satisfied that the national courts' assessment was one that properly fell within their margin of appreciation. ${ }^{91}{ } \gg$

Así justifica el TEDH que tanto el plazo de veinte años establecido por Noruega para la prescripción de las reclamaciones de reparación como los hechos que se encuentran en el origen de las reclamaciones no resultaban ser limitaciones arbitrarias, como alegaban los demandantes. En este punto se plantea una novedad en relación con la jurisprudencia del TEDH sobre el margen de apreciación, pues los comportamientos objeto de la reclamación no se encuentran entre los que han sido tradicionalmente objeto de la aplicación de esta doctrina ${ }^{92}$.

Si bien es cierto que el margen de apreciación nacional no se expresa en el Convenio Europeo, aparece tempranamente en la jurisprudencia del $\mathrm{TEDH}^{93}$, para permitir a los Estados parte que adopten limitaciones al ejercicio de un derecho, en situaciones excepcionales, siempre que resulten proporcionales a la propia esencia del derecho cuyo alcance es objeto de la restricción, de conformidad con el Convenio ${ }^{94}$. Esto no quiere decir que se trate de una capacidad estatal absoluta, al encontrarse sometido a la supervisión europea, debiendo el Tribunal «therefore ascertain whether the discretion afforded to the Government was overstepped $\gg^{95}$.

91 El párrafo transcrito se encuentra en la página 27 de la Decisión de inadmisión.

92 Ver GREER, S., op. cit. supra.

93 Aparece por vez primera en 1958, concretamente en asunto Grecia contra Reino Unido, en la que Grecia demanda al Reino Unido por entender que ha incumplido las obligaciones derivadas de este Tratado internacional en Chipre. Ver en el Annuaire de la Convention Européenne des Droits de l'bomme, 1858-1959, vol. 2, pp. 172 y ss.

94 Pascual Vives, F.J., «Margen de apreciación nacional...», op. cit. supra, pp. 232-234.

95 El texto transcrito se encuentra en el parágrafo 29 de la Sentencia de 1 de junio de 2006, en el asunto Fedorenko contra Ucrania, n ${ }^{\circ}$ 25921/02. El TEDH había expresado casi treinta años antes, en la Sentencia de 18 de enero de 1978 en el asunto Irlanda c. Reino Unido, Asunto $\mathrm{n}^{\mathrm{o}} 5310 / 71$, p. 71 , la misma idea conforme a la cual el margen de apreciación nacional no se entiende como capacidad ilimitada del Estado que sigue obligado por sus compromisos internacionales y el TEDH decidirá si se extralimita de la estricta medida en la que es lícita esta actuación. 
Así las cosas «la Corte debe autolimitarse si la solución adoptada tiene la razonable apariencia del buen Derecho en vez de sustituir al Estado demandado con sus propios puntos de vista ${ }^{96}$. Ello se debe, según estableció el propio TEDH en su Sentencia en el caso Irlanda c. Reino Unido, a que el Estado está mejor ubicado, por su contacto directo con la realidad social del país, para decidir algunas cuestiones, como por ejemplo cuando un peligro público amenaza la vida de la nación ${ }^{97}$.

La doctrina del margen de apreciación nacional, en tanto que concepto jurídicamente indeterminado, y su generosa aplicación ${ }^{98}$ produce una importante discrecionalidad del Tribunal ${ }^{99}$, pues la jurisprudencia no ha identificado el límite de esta doctrina, que permanece «very much veiled in a cloud of mistery ${ }^{100}$, y cuya aplicación, según García Roca, «deriva de la misma naturaleza de la tutela internacional $\gg^{101}$.

En relación con los hechos que fundamentan la reclamación podemos plantearnos dos cuestiones íntimamente relacionadas entre sí: la primera, respecto de la proporcionalidad de la medida estatal con el bien objeto de protección, que no es otro, recordemos, que discriminación sufrida y la repa-

96 GaRcia RoCA, J., «La muy discrecional doctrina del margen de apreciación nacional según el Tribunal Europeo de Derechos Humanos: soberanía e integración», en Teoría y realidad constitucional, $\mathrm{n}^{\circ} 20,2007$, pp. 117-143, la transcripción del texto se encuentra en la página 124.

97 Es la Sentencia de 18 de enero de 1978 en el asunto Irlanda c. Reino Unido, op. cit. supra. La idea del texto se encuentra en el parágrafo 163.

98 KRATOCHVIL, J., «The inflation of the margin of appreciation by the European Court of Human Rights», Netherlands Quarterly of Human Rights, vol. 23/3, p. 324 y ss. La idea del texto se encuentra en la página 325 .

99 En el mismo sentido se pronuncia García RoCA, quien en la página 118 de la obra citada supra, decía con relación al margen de apreciación que su «aplicación práctica y construcción teórica tienen contornos altamente discrecionales e imprecisos y, en consecuencia, no por ser una jurisprudencia necesaria, resulta menos controvertida. Más no es nada fácil ofrecer por el momento soluciones alternativas».

100 Id. Nota anterior

101 GarCia RoCA, J., «La muy discrecional doctrina del margen de apreciación nacional según el Tribunal Europeo de Derechos Humanos: soberanía e integración», en Teoría y realidad constitucional, $\mathrm{n}^{\circ}$ 20,2007, pp. 117-143, la transcripción del texto se encuentra en la página 121. Por su parte, BENAVIDES CASALS, M.A., «El consenso y el margen de apreciación en la protección de los derechos humanos», Revista Ius et Praxis, año 15, n 1, pp. 295 y ss., afirma en la página 301 que «allí donde no existe un mínimo común europeo para entender de una determinada manera el contenido de un derecho, se abre para el Estado un margen de acción que le permite fijar de acuerdo a circunstancias jurídicas, sociales y culturales el contenido alcance de ciertos derechos, a la espera por parte del TEDH de poder encontrar elementos nuevos que le permitan establecer contenidos que se integrarán al orden público europeo u serán por tanto aplicables a todos los Estados miembros del Consejo de Europa por igual». 
ración debida como consecuencia de una vulneración continuada de derechos humanos; la segunda, la naturaleza jurídica de la obligación adquirida por el Estado parte. En relación con ellos cabe una única respuesta: la discriminación alegada se fundamenta en un comportamiento cuya prohibición resulta inderogable, pues los hijos de soldados alemanes en territorio noruego fueron víctimas de comportamientos subsumibles en la categoría de torturas y otros tratos o penas crueles, inhumanos o degradantes, algunos de ellos, evidentemente antes de la entrada en vigor de la Convención para Noruega, pero mantenidos en un momento posterior. Al ser un derecho inderogable no hay proporcionalidad que pueda justificar la aplicación del margen de apreciación antes referido.

\section{La potencial aplicación al caso de otras normas internacionales}

Por último, podemos cuestionarnos si además de los derechos incorporados en el Convenio Europeo (fundamentalmente la discriminación de la que fueron víctimas los hijos de los soldados alemanes durante la ocupación de Noruega), el Estado pudo haber vulnerado algunas otras normas relacionadas con el Convenio Europeo. Es evidente que este texto normativo perfila y desarrolla parte de los derechos humanos reconocidos con carácter universal, de modo que su relación con otros textos internacionales resulta previsible, en la medida en que desde una perspectiva regional puede elevarse el umbral de protección establecido generalmente, pero nunca rebajarlo. Existe una clara dependencia del Convenio Europeo con la Declaración Universal de los Derechos Humanos, que prohíbe sin excepciones la práctica de la tortura o las penas o tratos crueles, inhumanos o degradantes (art. 5), así como la discriminación de la que fueron objeto los hijos de los soldados alemanes, el texto de la Declaración establece (art. 7), por lo demás, la titularidad de todas las personas del «derecho a igual protección contra toda discriminación que infrinja esta Declaración y contra toda provocación a tal discriminación.» En consecuencia, es clara la vulneración en este punto.

Por otra parte, el origen de la situación en la que tuvieron que sobrevivir estos niños se encuentra en la Segunda Guerra Mundial, por lo que su contexto de vulnerabilidad podría considerarse un efecto colateral de la contienda. En todo caso, cabría plantear la posibilidad de aplicar en este punto las normas de Derecho Humanitario a la situación en presencia debido al origen antes indicado. Desde una perspectiva subjetiva, la respuesta ha de ser afirmativa por 
cuanto Noruega fue parte en el Convenio IV de Ginebra ${ }^{102}$ tempranamente. Temporalmente, este Estado solo estaba obligado a su cumplimiento desde un momento posterior a su entrada en vigor para él, lo que se produjo a finales de 1951, por lo que, de ser aplicable, lo sería en relación a los hechos posteriores a este momento.

Más complicado resulta justificar la aplicabilidad sustantiva del texto considerado pues, por una parte, el apartado c del artículo 3 común a los Convenios de Ginebra proscribe en relación con los civiles que no participan en las hostilidades «los atentados contra la dignidad personal, especialmente los tratos humillantes y degradantes». Por otra, es cierto que el Convenio IV contiene algunas disposiciones aplicables en tiempos de paz, entre las que no se encuentra la que nos ocupa, ya que el artículo indicado formula obligaciones para los Estados parte en «caso de conflicto armado que no sea de índole internacional y que surja en el territorio» de cualquiera de ellas. Tampoco hacía falta extender la aplicación de la proscripción a los tiempos de paz, dado que ya se encontraba incorporada sin excepciones en la Declaración Universal, como vimos antes.

Tenemos que retener una última cuestión en este punto: en la medida en que el Convenio Europeo adopta como punto de partida de su texto a la propia Declaración Universal de Derechos Humanos, a la que se refiere en su preámbulo podríamos afirmar que cuando se somete a una discriminación en un Estado Europeo a una persona y ésta discriminación consiste en la práctica de torturas o penas o tratos inhumanos o degradantes, no sólo se está vulnerando el artículo tercero del Convenio Europeo, que así lo recoge, sino también la Declaración Universal y, a partir de la entrada en vigor del Pacto Internacional de Derechos civiles y políticos, también el artículo 7 de este texto. Recordemos, en este punto que la prohibición de la tortura y de la aplicación de penas o práctica de tratos inhumanos o degradantes es inderogable para todas las personas, en todo tiempo y lugar ${ }^{103}$.

102 Noruega ratificó el Convenio IV de Ginebra, de 12 de agosto de 1949, relativo a la protección de personas civiles en tiempo de guerra, el 3 de agosto de 1951, vid. en https://ihl-databases. icrc.org/applic/ihl/ihl.nsf/States.xsp?xp_viewStates=XPages_NORMStatesParties\&xp_treatySelected=380. El Convenio había entrado en vigor el 21 de octubre de 1950.

${ }^{103}$ En la actualidad, además, entre otros vulneraría también desde el 26 de junio de 1987, la Convención contra la tortura y otros tratos o penas crueles, inhumanos o degradantes y el artículo 4 de la Carta de Derechos Fundamentales, derecho originario ex artículo 6.1 del Tratado de la Unión Europea. 
Cuestión distinta de la anterior es la inexistencia de sistemas de control que permitan fiscalizar la eventual vulneración producida en momentos anteriores a la entrada en vigor de los tratados que incorporan las obligaciones objeto de incumplimiento, lo que infringiría el principio de legalidad en este punto. Sin embargo, al haberse consolidado la reiterada prohibición como norma consuetudinaria, la fiscalización de la misma producida en un momento anterior a la entrada en vigor de los tratados que la proclaman no vulneraría el principio indicado siempre que la costumbre existiera en un momento anterior a la realización de los actos considerados.

Por último, convengamos que los textos convencionales referidos carecen de sistemas de control de cumplimiento, con la salvedad del propio Convenio Europeo ya visto o del Pacto Internacional de Derechos civiles y políticos ${ }^{104}$, pero la inexistencia de sistema de fiscalización carece de repercusión sobre la consideración de un comportamiento como ilícito.

\section{CONCLUSIONES}

La situación de los hijos de los soldados alemanes de la Segunda Guerra Mundial en Noruega evidencia la vulnerabilidad de los niños, no solo en los conflictos armados, sino también en los momentos posteriores a ellos. El caso particular de los menores que se criaron en Lebensborn ilustra que es posible vulnerar los derechos de los más débiles durante la contienda, pues resulta claro que el sistema que implantó estos centros, a pesar del pronunciamiento del tribunal que juzgó el proceso $\mathrm{n}^{\mathrm{o}} 8$ de Nuremberg, infringió los derechos de estos menores muy gravemente, aunque en el contexto de la crueldad desarrollada en la Segunda Guerra Mundial, quizá quedara opacada por otras barbaridades cometidas en su transcurso. No es menos cierto que la vulneración de los derechos que pasaron por estos centros durante la contienda queda empequeñecida por la crueldad de una posguerra desarrollada sobre unas bases de odio frente a unos niños que fueron igualmente víctimas de los ocupantes y que no podían hacer nada por evitar el origen de esa estigmatización.

\footnotetext{
${ }^{104} \mathrm{El}$ primer informe presentado por Noruega está fechado el 6 de abril de 1977 y puede leerse en: https://tbinternet.ohchr.org/_layouts/treatybodyexternal/Download.aspx?symbolno=CCPR\% 2fC $\% 2 \mathrm{f} 1 \% 2 \mathrm{fAdd} .5$ \& Lang=en La comunicaciones individuales contra Noruega pueden presentarse desde el momento de la entrada en vigor del Primer protocolo facultativo al Pacto, dado que este Estado ratificó el texto en cuestión el 13 de septiembre de 1972.
} 
En el imaginario popular noruego se consideró que los hijos de los soldados alemanes con carácter general (incluidos los niños de Lebensborn), formaban parte de la peor de las especies: hijos y herederos de una mujer con problemas psiquiátricos (pues solo quienes los tuvieran podrían tener este tipo de relaciones con soldados alemanes) y de la maldad de sus padres, soldados ocupantes. A semejante carta de presentación se unió la venganza frente al ejército del que formó parte su padre provocó su discriminación en los entornos más próximos a ellos, incluso en sus propias familias, la particularidad de Noruega en este punto es que, a diferencia de lo ocurrido en sus territorios vecinos, esta estigmatización se vio protagonizada, alentada o tolerada por el propio Estado. En consecuencia, el Estado es responsable por los daños sufridos por estos niños, máxime cuando se decidió a rechazar la aplicación de las medidas que en su momento se indicaron al efecto para evitar que esta situación se produjera.

Un factor que pudo influir en el rechazo popular a los niños que nos ocupan pudo derivar del elevado número de centros del Proyecto en Noruega, solo comparable con los abiertos en Alemania. Asimismo, la relación durante la Guerra entre la población noruega (aproximadamente de tres millones en aquel momento) y de los efectivos desplazados a aquellas tierras (unos trescientos mil soldados) puede servirnos para hacernos una idea de la dureza de la ocupación. En todo caso, los niños fueron víctimas inocentes de una situación en cuya producción ellos no habían contribuido en modo alguno.

La situación en la que tuvieron que sobrevivir estos menores no solo durante su infancia, sino también en su edad adulta, evidencia, además, que los daños sufridos en la infancia son daños continuados en la medida en que, si se quiebran las bases fundamentales que permiten a las personas adquirir las herramientas necesarias para desarrollarse en el futuro, éste se quiebra de forma irreparable y, frente a estos daños no hay reparación posible. A pesar de lo cual, hemos de reconocer que se vulneraron sus derechos, pues si estamos de acuerdo en que el Tercer Reich infringió los derechos humanos de los niños polacos y de otros territorios ocupados, no podemos sino hacer lo propio con comportamientos objetivamente similares, agravados por su realización en los años posteriores a la contienda. Negar la vulneración en este supuesto podría alcanzar a la anterior, lo que no es cuestionable. Por otra parte, existía ya la convicción de la existencia de estos derechos cuando se produjeron todos estos hechos, como se ha indicado en las páginas precedentes.

Por otra parte, considero que el TEDH podría haber argumentado de un modo más convincente la inadmisión a la comunicación planteada, pues 
ha perdido la ocasión de visualizar un caso cuya reproducción quizá resulte difícil, pero nunca está de más recordar que hay líneas rojas, especialmente cuando se trata de derechos humanos, que no deben rebasarse. En un momento político como el actual resulta necesaria, desde mi punto de vista, la implicación de los tribunales en la lucha contra la xenofobia y la exclusión al diferente, cuando se enfrentan a casos como el presente, que les permite la posibilidad de hacerlo.

Por ello, a la luz de todo lo anterior, emerge con fuerza la necesidad de adquirir la convicción por parte de los Estados implicados en una contienda (o de las partes en un conflicto armado interno), de que a su finalización es imprescindible aplicar planes de reconciliación en los que se integren a los niños que hayan podido nacer de relaciones entre el vencedor y el vencido. Esto implica la obligación de los Estados de adoptar cuantas medidas resulten necesarias para preparar no solo a los propios menores afectados, sino también a las familias y comunidades a las que haya de reintegrarse para evitar que se vuelvan a estigmatizar a estos niños por su origen. Sólo adoptando medidas que permitan educar a todos los interesados en la relevancia de la reconciliación y de la condición de víctimas de la contienda de todos los implicados podrá producir una sociedad madura, seria y comprometida con los derechos humanos, porque solo de este modo podremos intentar alcanzar un futuro mejor para todos.

Sin embargo, la situación en este punto no es halagüeña, pues en los planes posconflicto se ignora a los hijos del enemigo. Por su parte, en la página de la Oficina del representante especial del Secretario General para los niños y los conflictos armados, en los efectos del conflicto se menciona a los niños desplazados internos, niños detenidos o la niña, pero en ningún momento hay mención a estos niños de la guerra. Resultan excluidos no en tanto que niño afectado por la guerra, que lo será como los demás, sino por ser niños cuya vulnerabilidad encuentra su origen en la contienda ${ }^{105}$.

La situación de los tratados internacionales no es diferente, pues el Protocolo opcional de la Convención sobre los derechos del niño acerca de la protección de los niños afectados por los conflictos armados guarda silencio al ignorar a los niños de la guerra.

\footnotetext{
${ }^{105}$ Ver en este sentido el Informe de Graça Machel, sobre el impacto de la guerra en los conflictos armados, de 1996, en https://www.unicef.org/graca/
} 
En consecuencia, considero que hay que dotar de visibilidad a estos menores y que deben ampliarse esos programas para que les alcancen y que no queden en una situación de vulnerabilidad e indefensión. Hay que concebir medidas que permitan la integración en una sociedad sólida e inclusiva de todas las víctimas. En este sentido, debería proveerse a las madres e hijos apoyo psicosocial para mantener el equilibrio emocional y la salud tanto física como psicológica. No se puede tolerar que produzcamos niños con poca salud psicológica por el solo hecho de ser hijo de su padre. Es cierto que es difícil prevenir los comentarios maliciosos o los actos de vandalismo contra los que son diferentes, pero ahora contamos con instrumentos que podrían favorecer la no repetición de los hechos anteriores: uno sería el contenido sustantivo de la Convención de Naciones Unidas sobre los derechos del niño. Este texto convencional incorpora, por una parte, la garantía estatal en el cumplimiento de los derechos reconocidos ${ }^{106}$; por otra, proclama el interés superior del niño como un principio fundamental cuando haya que adoptar una decisión que pueda afectar a un menor de edad; el último serían los sistemas de control establecidos por el mismo texto convencional, que nos permitiría identificar la potencial presencia de un riesgo de que una situación semejante pudiera reproducirse.

Sin embargo, la práctica es tozuda y se empeña en mostrarnos que, en aquellos lugares en los que ha habido conflictos armados recientemente (pensemos en Sudán, Ruanda, la antigua Yugoslavia o el protagonizado por el DAESH) la vulnerabilidad de los menores nacidos de las relaciones entre los ocupantes y las ocupadas, han seguido siendo víctimas de estigmatización en las comunidades a las que pertenecen sus madres. En muchos de estos lugares, especialmente en aquellas culturas que consideran que la identidad se transmite por línea paterna, se visualiza al hijo del enemigo como perteneciente al grupo paterno que ha sido el agresor, y en este caso, es el enemigo genocida, por lo que su futuro no será muy halagüeño. Máxime cuando en la práctica observamos que se suele omitir a los niños sistemáticamente en los procesos de reconciliación, no en vano ellos mismos tienden a sentirse culpables por lo que hicieron sus padres.

\footnotetext{
106 Así, proclama la obligación de los Estados parte de adoptar todas las medidas necesarias para «proteger al niño contra toda forma de perjuicio o abuso físico o mental, descuido o trato negligente, malos tratos o explotación, incluido el abuso sexual, mientras el niño se encuentre bajo la custodia de los padres, de un representante legal o de cualquier otra persona que lo tenga a su cargo.» (art. 19), así como la prohibición de torturas y tratos o penas crueles, inhumanas o degradantes (art. 37).
} 
Como en tantas otras cuestiones relacionadas especialmente con los derechos humanos, se advierte en ésta la insuficiencia del derecho como instrumento único para resolver problemas. Es cierto que es un elemento importante, pero sin protección, preparación y pedagogía las categorías jurídicas no funcionan porque pueden considerarse imposiciones exógenas para los grupos humanos por lo que sus integrantes tienden a rebelarse contra ellas. La educación es un importante instrumento para cambiar las percepciones, lo que de nuevo nos ubica ante la responsabilidad del Estado. 